\title{
Mesenchymal stem cells alleviate the early brain injury of subarachnoid hemorrhage partly by suppression of Notch1-dependent neuroinflammation: involvement of Botch
}

Wenchao Liu, Ran Li, Jian Yin, Shenquan Guo, Yunchang Chen, Haiyan Fan, Gancheng Li, Zhenjun Li, Xifeng Li, Xin Zhang, Xuying He and Chuanzhi Duan *i)

\begin{abstract}
Background: Activated microglia-mediated neuroinflammation has been regarded as an underlying key player in the pathogenesis of subarachnoid hemorrhage (SAH)-induced early brain injury (EBI). The therapeutic potential of bone marrow mesenchymal stem cells (BMSCs) transplantation has been demonstrated in several brain injury models and is thought to involve modulation of the inflammatory response. The present study investigated the salutary effects of BMSCs on EBI after SAH and the potential mechanism mediated by Notch1 signaling pathway inhibition.

Methods: The Sprague-Dawley rats SAH model was induced by endovascular perforation method. BMSCs $(3 \times$ $10^{6}$ cells) were transplanted intravenously into rats, and $\mathrm{N}$-[N-(3,5-difluorophenacetyl-L-alanyl)]-S-phenylglycine t-butyl ester (DAPT), a Notch1 activation inhibitor, and Notch1 small interfering RNA (siRNA) were injected intracerebroventricularly. The effects of BMSCs on EBI were assayed by neurological score, brain water content (BWC), blood-brain barrier (BBB) permeability, magnetic resonance imaging, hematoxylin and eosin staining, and Fluoro-Jade $C$ staining. Immunofluorescence and immunohistochemistry staining, Western blotting, and quantitative real-time polymerase chain reaction were used to analyze various proteins and transcript levels. Pro-inflammatory cytokines were measured by enzyme-linked immunosorbent assay.

Results: BMSCs treatment mitigated the neurobehavioral dysfunction, BWC and BBB disruption associated with $\mathrm{EBI}$ after $\mathrm{SAH}$, reduced ionized calcium binding adapter molecule 1 and cluster of differentiation 68 staining and interleukin (IL)-1 beta, IL-6 and tumor necrosis factor alpha expression in the left hemisphere but concurrently increased IL-10 expression. DAPT or Notch1 siRNA administration reduced Notch1 signaling pathway activation following SAH, ameliorated neurobehavioral impairments, and BBB disruption; increased BWC and neuronal degeneration; and inhibited activation of microglia and production of pro-inflammatory factors. The augmentation of Notch1 signal pathway agents and phosphorylation of nuclear factor-kB after SAH were suppressed by BMSCs but the levels of Botch were upregulated in the ipsilateral hemisphere. Botch knockdown in BMSCs abrogated the protective effects of BMSCs treatment on EBI and the suppressive effects of BMSCs on Notch1 expression.

(Continued on next page)
\end{abstract}

\footnotetext{
*Correspondence: doctor_duanzj@163.com

Department of Neurosurgery, Zhujiang Hospital, Southern Medical University,

The National Key Clinical Specialty, The Engineering Technology Research

Center of Education Ministry of China, Guangdong Provincial Key Laboratory

on Brain Function Repair and Regeneration, Guangzhou 510282, China
}

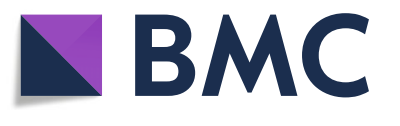

(c) The Author(s). 2019 Open Access This article is distributed under the terms of the Creative Commons Attribution 4.0 International License (http://creativecommons.org/licenses/by/4.0/), which permits unrestricted use, distribution, and

reproduction in any medium, provided you give appropriate credit to the original author(s) and the source, provide a link to the Creative Commons license, and indicate if changes were made. The Creative Commons Public Domain Dedication waiver (http://creativecommons.org/publicdomain/zero/1.0/) applies to the data made available in this article, unless otherwise stated. 
(Continued from previous page)

Conclusions: BMSCs treatment alleviated neurobehavioral impairments and the inflammatory response in EBI after

$\mathrm{SAH}$; these effects may be attributed to Botch upregulation in brain tissue, which subsequently inhibited the Notch1 signaling pathway.

Keywords: Subarachnoid hemorrhage, Mesenchymal stem cells, Early brain injury, Neuroinflammation, Notch1, Botch

\section{Background}

Subarachnoid hemorrhage (SAH) represents a lifethreatening cerebrovascular disease with high mortality and morbidity rates $[1,2]$. Although considerable efforts have shed light on the mechanisms involved in pathological events associated with SAH, the potential pathophysiological mechanisms are still poorly understood. Angiographic vasospasm and delayed ischemic neurological deficit were once regarded as the major cause of the unfavorable prognosis after SAH [3]; however, clinical trials revealed that the poor prognosis associated with SAH was not improved after use of anti-vasospastic drugs $[4,5]$. Recent advances in SAH research demonstrated that early brain injury (EBI), which refers to whole brain injury within the first $72 \mathrm{~h}$ post-SAH, was deemed as one of the major causes of mortality and unfavorable outcomes in SAH patients [6, 7]. As reported, multiple physiological abnormalities during EBI trigger the activation of inflammatory cascades, which result in blood-brain barrier (BBB) disruption and neuronal degeneration $[8,9]$. Therefore, it is critical to explore the mechanisms of neuroinflammation and to discover effective therapies targeting the neuroinflammatory processes in SAH $[10,11]$.

Mesenchymal stem cells (MSCs) have widely been used in experimental and clinical studies and have been demonstrated to have therapeutic potential in various system diseases such as ischemic stroke [12, 13], preterm brain injury [14], multiple sclerosis [15, 16], cardiac disease [17], and traumatic brain injury [18]. Exogenously transplanted MSCs migrated to damaged tissue sites, where they differentiated into several different lost or injured cell types and modulate immune responses [19, 20]. However, increasingly, recent evidence suggests that the protective effects of MSCs are mediated in a paracrine manner [21, 22]. It has been reported that MSCs administration inhibited microglia activation in several central nervous system (CNS) diseases $[23,24]$. Although the beneficial effects of bone marrow mesenchymal stem cells (BMSCs) transplantation at 14 days [25, 26] and at 21 days [27] post-SAH have previously been reported, to date and to the best of our knowledge, no studies have investigated the effects of BMSCs treatment on EBI after SAH or the possible underlying mechanisms.

The Notch1 signaling pathway plays an essential role in regulating cell fate decisions and in tissue homeostasis
[28-30]. Upon binding to its ligands Delta-1 or Jagged-1, the Notch1 receptor is cleaved by disintegrin-metalloprotease tumor necrosis factor (TNF)- $\alpha$-converting enzyme and $\gamma$-secretase complex, which releases the Notch1 intracellular receptor domain (NICD) from the membrane [31]. The NICD then translocates to the nucleus, where it interacts with the transcription factor recombining binding protein suppressor of hairless (RBP-JK), as wells as other regulators to modulate a variety of cellular metabolisms, such as cell proliferation and differentiation [32, 33]. In addition, increasing evidence indicates that Notch1 signaling may also play an essential role in activation of the inflammatory response in various diseases [34, 35]. Recent studies demonstrated that Notch1 signaling not only contributed to activated microglia-mediated neuroinflammation [36-38] but also aggravated neuronal degeneration [39], at least in part, via the nuclear factor- $\kappa B$ (NF- $k B$ ) signaling pathway during CNS diseases [40, 41]. MSCs transplantation has been demonstrated to suppress Notch1 signaling in ischemic stroke, inflammatory bowel disease, and lupus [42-44]. However, whether MSCs administration inhibits the Notch1 signaling pathway in EBI after $\mathrm{SAH}$ is unclear.

Cation transport regulator homolog 1 (Chac1) was identified as neuroprotective gene 7 (NPG7), recently renamed Botch-using functional cloning strategy [45]. As an endogenous blocker of Notch1 receptor, Botch inhibits the S1 furin-like cleavage of Notch1, thus promoting maintenance of full-length Notch1 [46]. Recent studies reported that Botch promoted neurogenesis through antagonizing the maturation of Notch1 during neocortical development and intracerebral hemorrhage $[47,48]$. However, whether Botch participates in the suppressive effects of BMSCs on Notch1 expression remains unexplored. Thus, we hypothesized that BMSCs treatment may alleviate the inflammatory response and neurodegeneration via inhibiting the Notch1 signaling pathway in EBI after SAH. We also investigated whether BMSCs treatment inhibited Notch1 activation in EBI after $\mathrm{SAH}$ through a mechanism involving the upregulation of Botch in brain tissue.

\section{Methods}

\section{Animals}

Adult male Sprague-Dawley rats (280-320 g) were purchased from the Animal Experiment Center of Southern 
Medical University (Guangzhou, China). The animals were bred and housed in controlled temperature and humidity conditions $\left(22 \pm 1{ }^{\circ} \mathrm{C}\right.$; $\left.40-60 \%\right)$ with a $12: 12$ dark/ light cycle (lights on at 07:00 h; off at 21:00 h), and food and water were available ad libitum. All experimental procedures were approved by the Southern Medical University Ethics Committee and were performed in accordance with the guidelines of the National Institutes of Health on the care and use of animals.

\section{Experimental design}

The experiments were performed as follows (Additional file 1).

\section{Experiment 1}

The impact of BMSCs administration on brain injury and neuroinflammation were assessed at 24 and $72 \mathrm{~h}$ after SAH. Neurological evaluation, brain water content (BWC), BBB permeability, magnetic resonance imaging (MRI), and hematoxylin and eosin (H\&E) staining were conducted at 24 and $72 \mathrm{~h}$ post-SAH. Neuronal degeneration and activated microglia-mediated neuroinflammation were separately examined by Fluoro-Jade C (FJC) staining, immunofluorescence (IF) staining, and enzyme-linked immunosorbent assay (ELISA). A total of 167 rats were randomly assigned into 5 groups: Sham 24 h group $(n=$ 24), SAH $24 \mathrm{~h}+$ phosphate buffer solution (PBS) group ( $n$ $=31)$, SAH $24 \mathrm{~h}+$ BMSCs group $(n=29)$, Sham $72 \mathrm{~h}$ group $(n=24)$, SAH $72 \mathrm{~h}+$ PBS group $(n=30)$, and SAH $72 \mathrm{~h}+$ BMSCs group $(n=29)$.

\section{Experiment 2}

To evaluate the time course of endogenous Notch1 and NICD expression after SAH, Western blotting was performed to detect Notch1 and NICD expression in the left hemisphere of each group. Double-labeling immunofluorescence of NICD and ionized calcium binding adapter molecule1 (Iba1)-positive microglia at $24 \mathrm{~h}$ post-SAH were conducted to determine the cellular localization of NICD. A total of 52 rats were randomly divided into following groups: Sham $(n=6)$, SAH $3 \mathrm{~h}(n=6)$, SAH $6 \mathrm{~h}(n=7)$, SAH $12 \mathrm{~h}(n=8)$, SAH $24 \mathrm{~h}(n=9)$, SAH $48 \mathrm{~h}(n=8)$, and SAH $72 \mathrm{~h}(n=8)$.

\section{Experiment 3}

To evaluate the effects of $N$-[N-(3,5-difluorophenacetyl-L-alanyl)]-S-phenylglycine $t$-butyl ester (DAPT), a $\gamma$-secretase inhibitor, on brain injury and neuroinflammation at $24 \mathrm{~h}$ post-SAH, Western blotting, IF staining, and immunohistochemistry (IHC) staining were used to assess the inhibitory effect of DAPT on Notch1 signaling pathway. Following injection of DAPT, neurological evaluation, BWC, FJC, and NeuN staining and ELISA were performed at $24 \mathrm{~h}$ post-SAH as follows: Sham group $(n=24)$, SAH $24 \mathrm{~h}$ group $(n=31)$, SAH $24 \mathrm{~h}+$ dimethylsulfoxide (DMSO) group $(n=31)$, and $\mathrm{SAH}$ $24 \mathrm{~h}+$ DAPT group $(n=29)$.

\section{Experiment 4}

To assess the impact of knockdown of endogenous Notch1 in vivo on brain injury and neuroinflammation after $24 \mathrm{~h} \mathrm{SAH}$, we assessed the inhibitory effect of Notch1 small interfering RNA (siRNA) on Notch1 signaling pathway by using quantitative real-time polymerase chain reaction (qRT-PCR), Western blotting, IF, and IHC staining. Notch1 siRNA administration was conducted at $48 \mathrm{~h}$ before modeling, and then neurological evaluation, BWC, FJC staining, NeuN staining, and ELISA were performed at $24 \mathrm{~h}$ post-SAH. A total of 130 rats were randomly divided into 4 groups: Sham $(n=$ 27), SAH $24 \mathrm{~h}(n=35)$, SAH $24 \mathrm{~h}+$ scramble siRNA ( $n$ $=35)$, and SAH $24 \mathrm{~h}+$ Notch 1 siRNA $(n=33)$.

\section{Experiment 5}

To validate the hypothesis that the Notch1 signal pathway participates in the protective mechanism of BMSCs on EBI after SAH, we detected the expression of endogenous Notch1 using Western blotting, qRT-PCR, and IF staining at 24 and $72 \mathrm{~h}$ post-SAH. A total of 55 rats were randomly assigned into 5 groups: Sham $(n=9)$, SAH $24 \mathrm{~h}+\mathrm{PBS}(n$ $=12)$, SAH $24 \mathrm{~h}+$ BMSCs $(n=11)$, SAH $72 \mathrm{~h}+\operatorname{PBS}(n=$ $12)$, and SAH $72 \mathrm{~h}+$ BMSCs $(n=11)$.

\section{Experiment 6}

To detect the potential mechanism of the inhibitory effect of BMSCs on Notch1 signaling after SAH, Botch protein and mRNA levels were quantitatively analyzed at 24 and $72 \mathrm{~h}$ post-SAH with or without BMSCs treatment. Furthermore, we knocked down Botch expression in BMSCs and then transplanted them intravenously through the left femoral vein; efficiency of gene knockdown was assessed with Western blotting and qRT-PCR. The effects of BMSCs with attenuated Botch on neurobehavioral deficits and BWC were estimated at $24 \mathrm{~h}$ after $\mathrm{SAH}$. A total of 56 rats were randomly divided into 3 groups: SAH + PBS $(n=19)$, SAH + BMSCs $(n=18)$, and SAH + BMSCs sh-Botch $(n=19)$.

\section{$\mathrm{SAH}$ rat model}

The SAH model in rats was induced as described previously with small modifications [49]. In brief, with anesthetized rates by intraperitoneal injection of pentobarbital sodium $(45 \mathrm{mg} / \mathrm{kg})$ and maintained a core temperature at $37.5^{\circ} \mathrm{C}$. A $3-0$ monofilament suture was advanced centripetally through the left external carotid artery (ECA), the common carotid artery, and the internal carotid artery (ICA) to perforate the intracranial bifurcation of the ICA. After SAH, the suture was withdrawn into the ECA then 
perfused the ICA. Sham-operated rats underwent the same procedures except that the suture was inserted beyond the point once resistance was felt. At the end of the surgical procedure, rats were allowed to recover on a heated blanket and then returned to separate cages with free access to food and water.

\section{BMSCs isolation, identification, and gene modification}

BMSCs were isolated and cultured as previously described [50]. Briefly, the femora and tibias were dissected from both knees of adult male spontaneous hypertensive Sprague-Dawley rats weighing $80-100 \mathrm{~g}$. The bone marrow plugs were then rinsed from the medullary cavity using a 10-mL syringe with Dulbecco's modified Eagle's medium-low glucose (Sigma-Aldrich, St. Louis, MO,USA) supplemented with $10 \%$ fetal bovine serum (Biocell, Rancho Dominguez, CA,USA). The bone marrow cell suspension was centrifuged at $400 \times g$ for $20 \mathrm{~min}$ to obtain mononuclear cells. The mononuclear cells were cultured in culture flasks with a density of $1 \times 10^{6}$ cells $/ 25 \mathrm{~cm}^{2}$ at $37{ }^{\circ} \mathrm{C}$ with $5 \% \mathrm{CO}_{2}$. When the cells reached $90 \%$ confluency, the adherent cells were trypsinized and expanded. BMSCs passaged four times were used in the subsequent experiments. Typical positive BMSCs markers (CD29, CD44, and CD90) and a negative marker (CD45) were tested by flow cytometry analysis. Antibodies were purchased from BD Biosciences (555005, dilution 1:10; 550974, dilution 1:10; 551401, dilution 1:10; 551402, dilution 1:10 respectively, San Jose, CA, USA).

During the first passage, BMSCs were transfected with lentivirus at a multiplicity of infection of eight [51]. BMSCs transfected with Botch short hairpin RNA (shRNA) lentivirus were defined as BMSCs sh-Botch and transfected with mock lentivirus were defined as negative control (NC) group (BMSCs sh-NC). Polybrene $(10 \mu \mathrm{g} / \mathrm{mL})$ was incubated to achieve the optimal gene transfer, and qRT-PCR and Western blotting of Botch production confirmed the efficiency of gene transduction in BMSCs sh-Botch.

\section{BMSCs transplantation}

BMSCs were delivered intravenously into rats within $1 \mathrm{~h}$ after induction of SAH as previously described. First, the femoral vein was dissected and exposed with blunt dissection. BMSCs $\left(3 \times 10^{6}\right.$ cells $)$ were then suspended in $1 \mathrm{~mL}$ PBS and were injected slowly via the femoral vein for $5 \mathrm{~min}$. The needle was then removed, the femoral vein was ligated, and the incision was closed carefully. As the control group, rats were infused with equal amount of PBS without BMSCs.

\section{Intracerebroventricular injection}

Injection of DAPT and Notch1 siRNA into the lateral ventricle was performed as previously described [52].
Briefly, rats were anesthetized and placed on a stereotaxic frame. A midline skin incision was performed and a $10-\mu \mathrm{L}$ microsyringe (Shanghai High Pigeon Industry \& Trade Co., Ltd., Shanghai, China) was inserted into the left lateral ventricle via a burr hole, which was drilled according to the coordinates relative to bregma: $1.5 \mathrm{~mm}$ posterior, $1.0 \mathrm{~mm}$ lateral, and $3.2 \mathrm{~mm}$ below the horizontal plane of bregma. Following the manufacturer's instructions, DAPT (Sigma-Aldrich) was dissolved in DMSO at $1 \mathrm{mg} / \mathrm{mL}$. DAPT and vehicle (DMSO) were administered slowly at $1 \mu \mathrm{L} / \mathrm{min}$ into the left lateral ventricle after 90 min SAH [53]. The microsyringe was kept in place for an additional 5 min after administration and then withdrawn slowly. Lastly, the burr hole was closed by bone wax and the incision was sutured carefully. Notch1 siRNA (sc-270189, Santa Cruz Biotechnology, CA, USA) and scramble siRNA were separately dissolved in transfection reagent (Entranster TM-in vivo, 18668-11-1, Engreen Biosystem Co, Ltd., Beijing, China) at $0.45 \mu \mathrm{g} / \mu \mathrm{L}$ and then infused at $48 \mathrm{~h}$ before the induction of SAH.

\section{Neurological score evaluation and SAH grade}

Neurological scores (neurobiological deficits) were evaluated by an independent investigator blinded to procedure information using the modified Garcia test [54, 55]. In the Garcia test, six sensorimotor tests including spontaneous activity, spontaneous movement of all limbs, forelimbs outstretching, climbing, touch of trunk, and vibrissae touch were assessed. Every test was scored as 0 to 3 , and the total scores ranged from 0 to 18 . Higher scores represent lighter neurological deficits.

Evaluation of SAH severity was performed blindly with an SAH grading system as previously reported. The basal surface of the brain was divided into six parts, and each part was scored 0 to 3 based on the amount of subarachnoid blood. Total scores ranged from 0 to 18 and mild SAH rats (total scores $<8$ ) were subsequently eliminated from the study because there were no significant difference neurological impairments between sham and both treated and untreated mild SAH groups [55].

\section{MRI}

At 24 and $72 \mathrm{~h}$ post-SAH, $\mathrm{T}_{2}$-weighted images were acquired using a 7.0-T small animal PharmaScan 70/16 MRI scanner (Bruker, MA, USA) according to the following parameters: repetition time (TR)/echo time (TE) $=4000 / 96 \mathrm{~ms} ;$ scan time $=2 \mathrm{~min}$; field of view $35 \times$ $35 \mathrm{~mm}$, matrix $256 \times 256 \mathrm{~mm}$; coronal slice thickness $=$ $1.0 \mathrm{~mm}$; and number of slices $=25[56,57]$.

\section{BWC}

At 24 and $72 \mathrm{~h}$ post-SAH, brains were removed and divided quickly into four segments: left hemisphere, right 
hemisphere, cerebellum, and brain stem. Every segment was weighed immediately to obtain the wet weight (WW), and then dried in an oven for $72 \mathrm{~h}$ at $105{ }^{\circ} \mathrm{C}$ to obtain the dry weight (DW). The percentage of $\mathrm{BWC}=$ $[(\mathrm{WW}-\mathrm{DW}) / \mathrm{WW}] \times 100 \%$.

\section{BBB permeability}

$\mathrm{BBB}$ disruption was evaluated on the basis of Evans Blue dye extravasation as previously described [58]. Briefly, $2 \%$ Evans Blue dye $(4 \mathrm{~mL} / \mathrm{kg}$ was injected intravenously after at 24 and $72 \mathrm{~h}$ post-SAH) was administered over 2 min into the left femoral vein and circulated for $2 \mathrm{~h}$. Under deep anesthesia, the brains were harvested and separated immediately into the left and right cerebral hemispheres. Subsequently, the brain samples were weighed, homogenized in 50\% trichloroacetic acid solution $(2 \mathrm{~mL})$, and centrifuged at $15,000 \times \mathrm{g}$ for $30 \mathrm{~min}$. The supernatant was mixed with ethanol (1:3) and incubated overnight at $4{ }^{\circ} \mathrm{C}$. After centrifugation $(15,000 \times g$ for $30 \mathrm{~min})$, the resultant supernatant was spectrophotometrically quantified for the fluorescence intensity of Evans Blue dye at an excitation wavelength of $620 \mathrm{~nm}$, an emission wavelength of $680 \mathrm{~nm}$, and a band width of $10 \mathrm{~nm}$.

\section{H\&E staining}

At $24 \mathrm{~h}$ and $72 \mathrm{~h}$ post-SAH, rats were anesthetized and transcardially perfused with $250 \mathrm{~mL}$ PBS $(0.1 \mathrm{M}, \mathrm{pH}$ 7.4) followed by $500 \mathrm{~mL} 4 \%$ paraformaldehyde as previously described [59]. The brains were removed immediately and post-fixed in the same fixative for $24-48 \mathrm{~h}$ at $4{ }^{\circ} \mathrm{C}$ and embedded in paraffin and cut in serial coronal section ( $4 \mu \mathrm{m}$ thickness). Sections were then deparaffinized and rehydrated, and were stained with hematoxylin for $5 \mathrm{~min}$ and eosin for $10 \mathrm{~s}$. The slices were visualized and captured on a microscope (Leica-DM2500, Wetzlar, Germany).

\section{IF staining}

Four-micron-thick brain coronal sections were prepared as described earlier, deparaffinized in xylene, rehydrated via alcohol gradients, and washed with PBS $(0.01 \mathrm{M}, \mathrm{pH}$ 7.4). Following antigen retrieval, the sections were blocked in 5\% bovine serum albumin for $30 \mathrm{~min}$ at room temperature (RT) and incubated with primary antibodies as follows: rabbit anti-activated Notch1 (1:200; Ab52301, Abcam, Cambridge, UK); goat anti-Iba1 (1:300; Ab5076, Abcam); mouse anti-CD68 (1:200; Ab31630, Abcam); rabbit anti-NeuN (1:200, 24307T, Cell Signaling Technology, Danvers MA, USA) overnight at $4{ }^{\circ} \mathrm{C}$. The next day, the slices were washed with PBS and incubated with secondary antibodies: donkey anti-goat Alexa 488 (1:500; A11055, Invitrogen), donkey anti-rabbit Alexa 555 (1:500; A31572, Invitrogen), donkey anti-mouse Alexa
488 (1:500; A21202, Invitrogen), donkey anti-goat Alexa 555 (1:500; A21432, Invitrogen), goat anti-mouse Alexa 555 (1:500; A21422, Invitrogen), and donkey anti-rabbit Alexa 488 (1:500; A21206, Invitrogen) for $1 \mathrm{~h}$ at RT. After washing with PBS three times, the sections were stained by 4'6-diamidino-2-phenylindole for $10 \mathrm{~min}$ at room temperature and observed under a fluorescence microscope (Leica-DMI8, Leica Microsystems, Wetzlar, Germany).

\section{IHC staining}

The deparaffinized and rehydrated coronal sections ( $4 \mu \mathrm{m}$ thickness) were prepared as described earlier. Endogenous peroxidase activity was quenched using 3\% $\mathrm{H}_{2} \mathrm{O}_{2}$ for $10 \mathrm{~min}$ at RT. Sections were then blocked in $5 \%$ bovine serum albumin for $20 \mathrm{~min}$ and were incubated overnight at $4{ }^{\circ} \mathrm{C}$ with the following primary antibodies: rabbit anti-RBP-JK (1:200; 5313T, Cell Signaling Technology) and rabbit anti-Hes-1 (1:200; 11988s, Cell Signaling Technology). Brain slices were then washed with PBS and incubated with biotinylated goat anti-rabbit IgG (1:100; ZSGB-Bio, Beijing, China) for $10 \mathrm{~min}$ at RT. Next, brain slices were incubated with horseradish peroxidase-streptavidin reagent for $10 \mathrm{~min}$ and developed using diaminbenzidine peroxidase substrate. Images were captured on a light microscope (Leica-DM2500, Wetzlar, Germany).

\section{FJC staining}

FJC staining was performed to identify degenerated neurons as previously reported [59]. Briefly, brain sections were washed with alcohol solution ( $1 \%$ sodium hydroxide in $80 \%$ ethanol) followed by $70 \%$ ethanol and then immersed in $0.06 \%$ potassium permanganate solution for $10 \mathrm{~min}$. Subsequently slides were transferred into a 0.0001\% FJC (AG325, Millipore, Darmstadt, Germany) working solution for $30 \mathrm{~min}$ then cleared in xylene and coverslipped with permount TM mounting medium (Cwbiotech, Guangzhou, China). Images were obtained using a fluorescence microscope (Leica-DMI8, Leica Microsystems, Wetzlar, Germany).

\section{Western blotting}

At 24 and $72 \mathrm{~h}$ post-SAH, rats were transcardially perfused with ice-cold PBS (0.1 M, pH 7.4) and the ipsilateral cortex was quickly dissected for western blot analysis as described previously [60]. Briefly, protein samples from the left cerebral cortex or BMSCs were isolated and prepared using RIPA lysis buffer (Cwbio, Guangzhou, China) and the total protein concentration was measured with a bicinchoninic acid protein assay kit (Genecopoeia, Rockville, MD, USA). Equal amounts of protein $(50 \mu \mathrm{g})$ from different samples were separated by sodium dodecyl sulfate polyacrylamide gel 
electrophoresis (Cwbio, Guangzhou, China) and transferred to a polyvinylidene difluoride filter membrane. Membranes were then blocked in 5\% non-fat milk dissolved in Tris-buffered saline with $0.1 \%$ Tween 20 for $2 \mathrm{~h}$ and membranes were incubated with the following primary antibodies: mouse anti-Notch1 (1:1000, SC-376403, Santa Cruz Biotechnology); rabbit anti-activated Notch1 (1:1000, Ab52301, Abcam); mouse anti-RBP-JK (1:1000, SC-271128, Santa Cruz Biotechnology); rabbit anti-Hes-1 (1:1000, Ab108937, Abcam); rabbit anti-NF-kB P65 (1:1000, \#3033, Cell Signaling Technology); rabbit anti-phospho-NF-кB P65 (1:1000, \#8242, Cell Signaling Technology); mouse anti-Botch1 (1:500, N116/14, NeuroMeb, Davis, CA USA); and rabbit anti- $\beta$-actin (1:1000, \#8475, Cell Signaling Technology) overnight at $4{ }^{\circ} \mathrm{C}$ and then washed for $10 \mathrm{~min}$ three times in Tris-buffered saline with $0.1 \%$ Tween 20 . Afterwards, the blots were incubated with secondary antibodies: peroxidase-conjugated goat anti-rabbit IgG and goat anti-mouse IgG (1:10000, Bioss, Beijing, China) and identified using the ECL Western blotting detection system (Millipore, Darmstadt, Germany). The intensities of blots were analyzed with ImageJ software (ImageJ 1.5, National Institutes of Health, Bethesda, MD, USA). $\beta$-actin was used as the internal loading control.

\section{qRT-PCR}

Rat brain samples were homogenized in Trizol reagent (Sigma-Aldrich) according to the manufacturer's instructions. Total RNA was isolated and reverse transcribed to cDNA with a primescript RT reagent kit (RR047A, Takara Bio Inc., Shiga, Japan). For qRT-PCR, the 7500 Real-Time PCR thermocycler (Applied Biosystem) was used. Real-time RT-PCR was performed in a total volume of $10 \mu \mathrm{L}$ containing $1 \mu \mathrm{L}$ of cDNA, $0.6 \mu \mathrm{L}$ of primers, and 8.4 $\mu \mathrm{L}$ of SYBR Green PCR Master Mix (RR820A, Takara Bio Inc.). The program steps for amplification were pre-denaturation at $95^{\circ} \mathrm{C}$ for $30 \mathrm{~s}, 40$ cycles of $95{ }^{\circ} \mathrm{C}$ for $3 \mathrm{~s}$, and extension at $60{ }^{\circ} \mathrm{C}$ for $30 \mathrm{~s}$. The mean levels of target genes were calculated using the relative normalized expression with $\beta$-actin used as internal control. The primer sequences are listed as Table 1.

\section{ELISA}

At $24 \mathrm{~h}$ and $72 \mathrm{~h}$ post-SAH, rats were anesthetized and transcardially perfused with $250 \mathrm{~mL}$ PBS, the left hemisphere was harvested immediately and homogenized in $0.9 \%$ normal saline at $200 \mathrm{mg} / \mathrm{mL}$ and centrifuged at $12,000 \times g$ for $20 \mathrm{~min}$. The supernatant was collected and stored in $-80{ }^{\circ} \mathrm{C}$ until further used. The concentrations of TNF- $\alpha$, interleukin (IL)-6, IL-1 $\beta$, and IL-10 in brain tissue lysates were analyzed using commercial ELISA kits (BMS625, BMS630, and BMS629, Invitrogen)
Table 1 Real-time PCR primers used for quantification of mRNA expression in this study

\begin{tabular}{lll}
\hline Primer name & Sequence $\left(5^{\prime} \rightarrow 3^{\prime}\right)$ \\
\hline Notch1 & Forward & GTGTGGAAAAGCCCGTGTC \\
& Reverse & GCACAAGGTTCTGGCAGTTG \\
RBP-Jk & Forward & CACGTTCCATGAGGGAGTGG \\
& Reverse & TGGCATTTGGTAATTCCTTGC \\
Hes-1 & Forward & GCTGCTACCCCAGCCAGTG \\
& Reverse & GCCTCTTCTCCATGATAGGCTTG \\
Botch & Forward & TGGATTTCGGGTACGGCTC \\
& Reverse & GTCTGCCAAACGCAACAAGT \\
B-actin & Forward & TCAGCAAGCAGGAGTACGATG \\
& Reverse & GTGTAAAACGCAGCTCAGTAACA \\
\hline
\end{tabular}

according to the manufacturer's instructions. The final concentration of cytokines was interpolated from the determined standard curve of absorbance.

\section{Statistical analysis}

All data were shown as means \pm standard error of the mean (SEM) and analyzed using SPSS version 19.0 software (SPSS, IBM, Armonk, NY, USA). After checking for normal distribution, the statistical significance of two groups was determined using Student's $t$ test or Mann-Whitney $U$ test; one-way analysis of variance (ANOVA) followed by Tukey's post-hoc test or Kruskal-Wallis followed by Dunn's test were applied for comparison of multiple groups; $P<0.05$ was considered statistically significant. Cartograms were drawn using GraphPad Prism 5 software (GraphPad Software, Inc., San Diego, CA, USA).

\section{Results}

Characterization of rat BMSCs and representative macrographs

Flow cytometry was used to characterize BMSCs by determining surface antigens expression (Fig. 1a, b). BMSCs were positive for CD90 (99.7\%), CD29, (99.21\%), and CD44 (74.27\%), but were negative for CD45 (2.52\%). Representative images of brains from rats in Sham and SAH groups are shown in (Fig. 1c). We specifically focused on the basal cortex of the left hemisphere (Fig. 1d).

\section{BMSCs transplantation attenuated neurobehavioral deficits and reduced histological damage at 24 and $72 \mathrm{~h}$ after $\mathrm{SAH}$}

Rats in the SAH + PBS groups showed severe behavioral deficits (Fig. 2a) and higher levels of cerebral edema (Fig. 2b), compared with rats in the Sham group at $24 \mathrm{~h}$ and at $72 \mathrm{~h}$ post-SAH. Transplantation of BMSCs improved behavioral performance and reduced edema in 

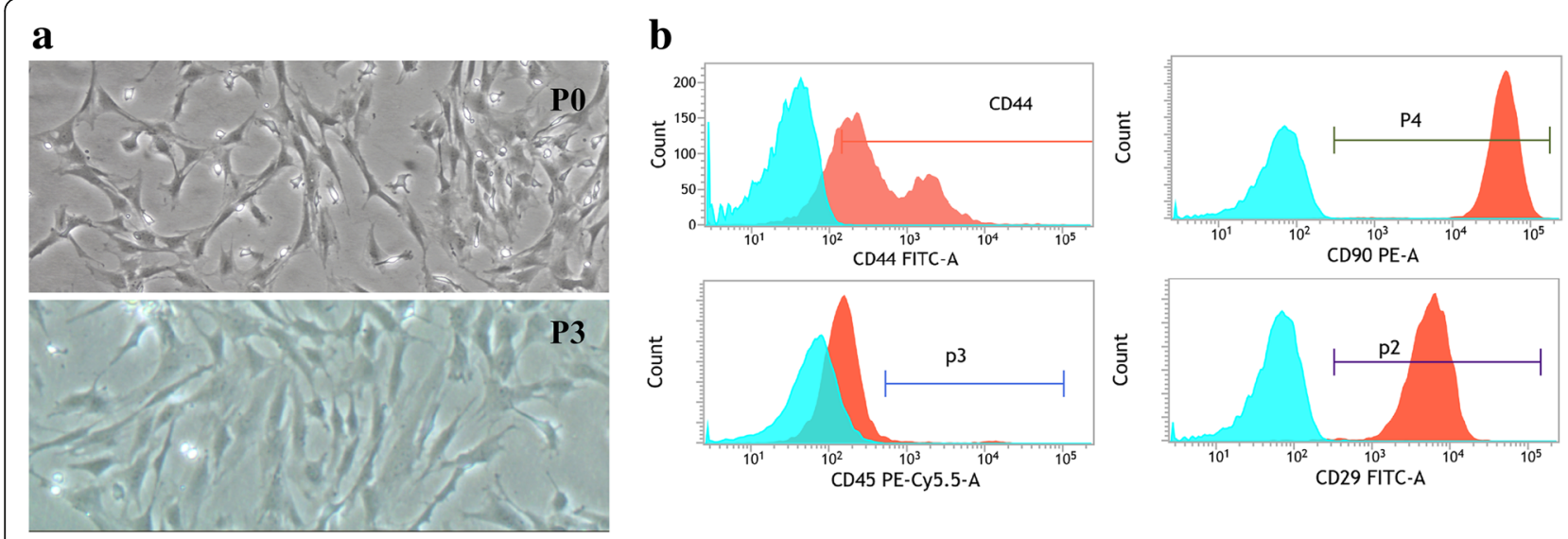

\section{c}

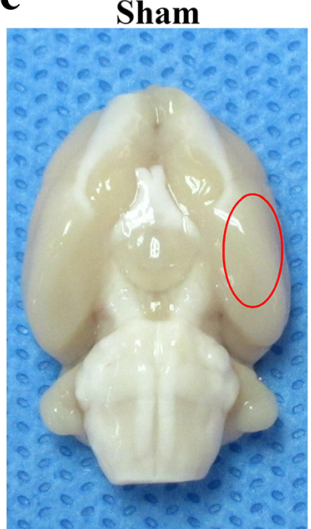

SAH

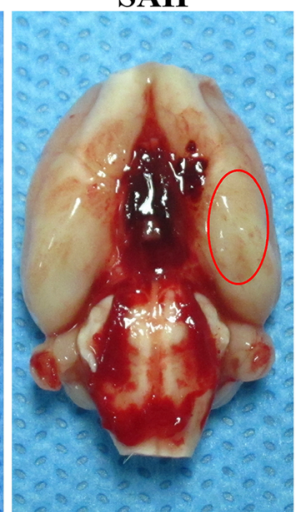

\section{d}

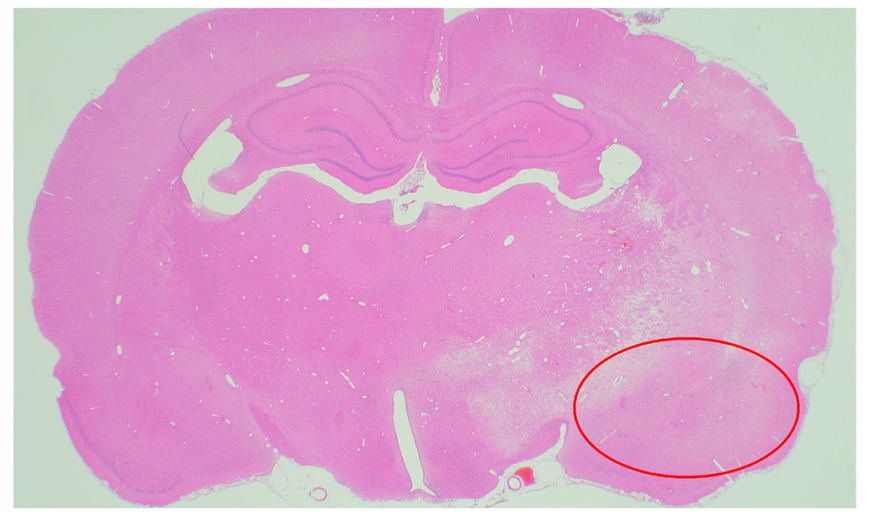

Fig. 1 Identification of rat BMSCs and representative image of subarachnoid hemorrhage (SAH) model. Representative micrographs of BMSCs cultured at passage 0 (P0) and passage 3 (P3) (a). Flow cytometry analysis indicating positive BMSCs markers (CD29, CD44, CD90) and a negative marker (CD45) (b). Representative picture of brains from the Sham and SAH groups (c). A schematic indicating the optimal brain region for immunochemistry staining, qRT-PCR and western blotting (red circle) (d). CD, cluster of differentiation

brain tissue, compared with $\mathrm{SAH}+\mathrm{PBS}$ group. $\mathrm{H} \& \mathrm{E}$ staining (Fig. 2c) and MRI $\mathrm{T}_{2}$-weighted images (Fig. 2d) were also used to evaluate the effect of BMSCs administration at $24 \mathrm{~h}$ and $72 \mathrm{~h}$ post-SAH; the results indicated that BMSCs transplantations alleviated histological impairments.

\section{BMSCs administration alleviated disruption to the BBB and attenuated neuronal injury at $24 \mathrm{~h}$ and $72 \mathrm{~h}$ post- SAH}

Evans Blue dye extravasation was significantly decreased in the left hemisphere following BMSCs treatment compared with the SAH + PBS group (Fig. 2e). To further investigate the protective effects of BMSCs treatment on EBI after SAH, we estimated neuronal loss and degeneration (Fig. 2f). At $24 \mathrm{~h}$ and $72 \mathrm{~h}$ post-SAH, FJC-positive neurons were frequently present in the cortical region of the ipsilateral hemisphere. Administration of BMSCs significantly decreased the number of FJC-positive neurons and increased the NeuN-positive neurons.
Treatment with BMSCs inhibited microglia activation and decreased expression of inflammatory cytokines at $24 \mathrm{~h}$ and $72 \mathrm{~h}$ post-SAH

We performed co-staining of NeuN and CD68 (activated microglia/macrophage markers) as well as $\mathrm{NeuN}$ and Iba1 (labeled total microglia) to evaluate the microglia response after induction of SAH. Iba1- and CD68-positive cells were increased and NueN-positive cells were decreased after SAH (Additional file 2). BMSCs treatment decreased the Iba1-positive cells as well as CD68-positive cells in left hemisphere at $24 \mathrm{~h}$ and $72 \mathrm{~h}$ (Fig. 3a).

To further ascertain the effects of BMSCs on suppression of neuroinflammation, we examined several inflammatory cytokine levels in the ipsilateral hemisphere at 24 and $72 \mathrm{~h}$ post-SAH. BMSCs treatment significantly reduced the expression of the proinflammatory cytokines, IL- 6 , IL- $1 \beta$, and TNF- $\alpha$ (Fig. 3b-d) but elevated the expression of the ant-inflammatory cytokine, IL-10 (Fig. 3e). 


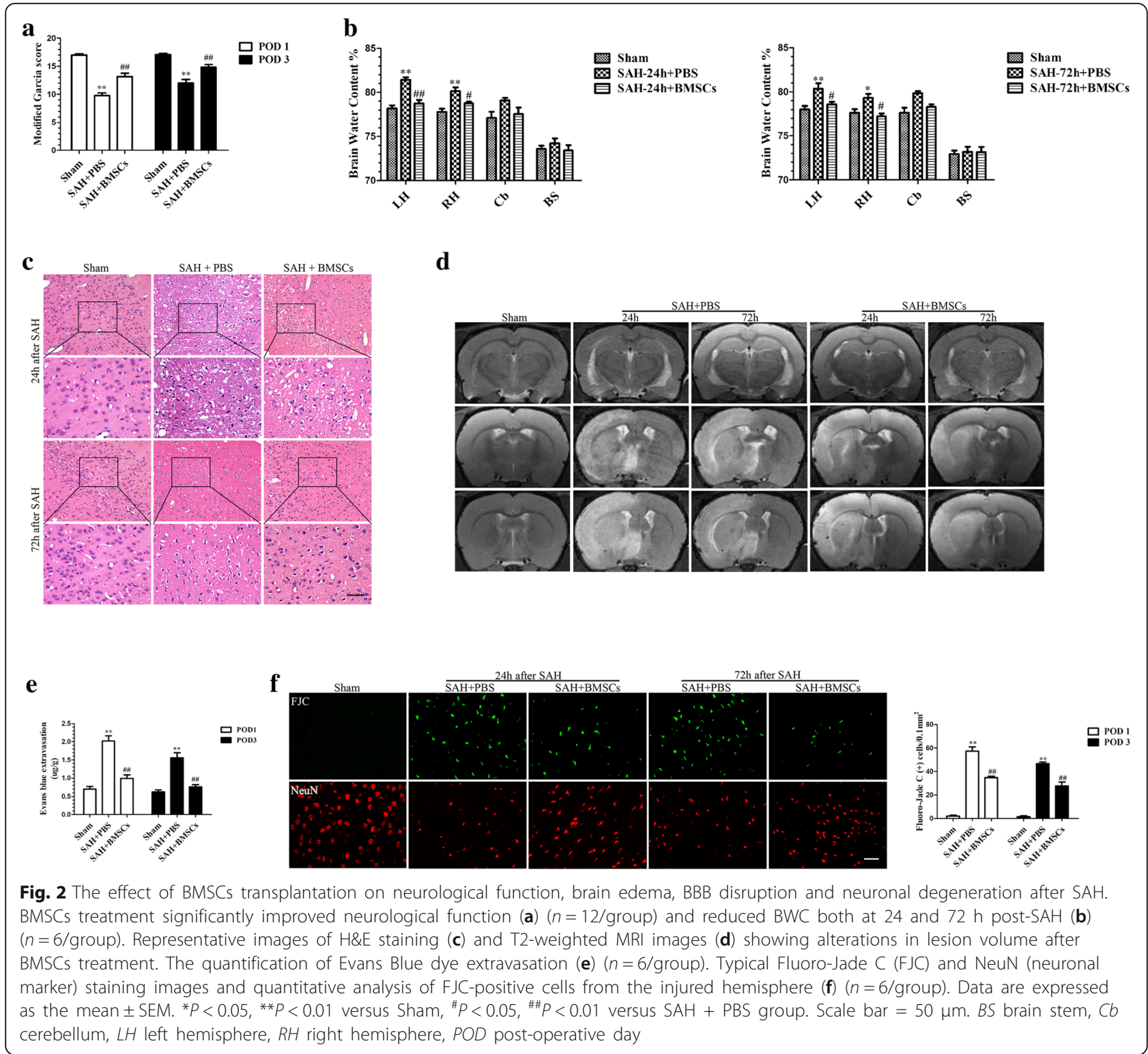

\section{Endogenous expression of Notch1 and its intracellular domain NICD after SAH}

Western blotting was performed to investigate the endogenous expression of Notch1 and NICD in the left hemisphere with $(3,6,12,24,48$, and $72 \mathrm{~h})$ and without SAH. Notch1 levels were elevated immediately after $\mathrm{SAH}$, reached a peak at $24 \mathrm{~h}$, and gradually declined at $48 \mathrm{~h}$ and $72 \mathrm{~h}$ (Fig. $4 \mathrm{a}, \mathrm{b}$ ). NICD levels increased from $12 \mathrm{~h}$ post-SAH, peaked at $24 \mathrm{~h}$, and was reduced significantly at $72 \mathrm{~h}$ (Fig. 4a, c). Double immunofluorescence staining showed that NICD was predominantly expressed in microglia in the cortex of ipsilateral hemisphere at $24 \mathrm{~h}$ post-SAH (Fig. 4d).

\section{DAPT inhibited the Notch 1 pathway at $24 \mathrm{~h}$ post-SAH}

Western blotting analysis showed that DAPT inhibited Notch1 expression at $24 \mathrm{~h}$ post-SAH. As NICD production is dependent on the enzymatic activity of the $\gamma$-secretase complex, DAPT administration significantly suppressed NICD accumulation. In the DAPT-treated group, RBP-JK and Hes family basic helix loop helix transcription factor 1 (Hes-1) were inhibited compared with the SAH + DMSO group (Fig. 5a-e). Consistent with the results of Western blotting, double immunofluorescence staining revealed that NICD expression in activated microglia was reduced following DAPT injection at $24 \mathrm{~h}$ post-SAH (Fig. 5f). IHC staining revealed that RBP-JK and Hes-1 were markedly increased at $24 \mathrm{~h}$ 


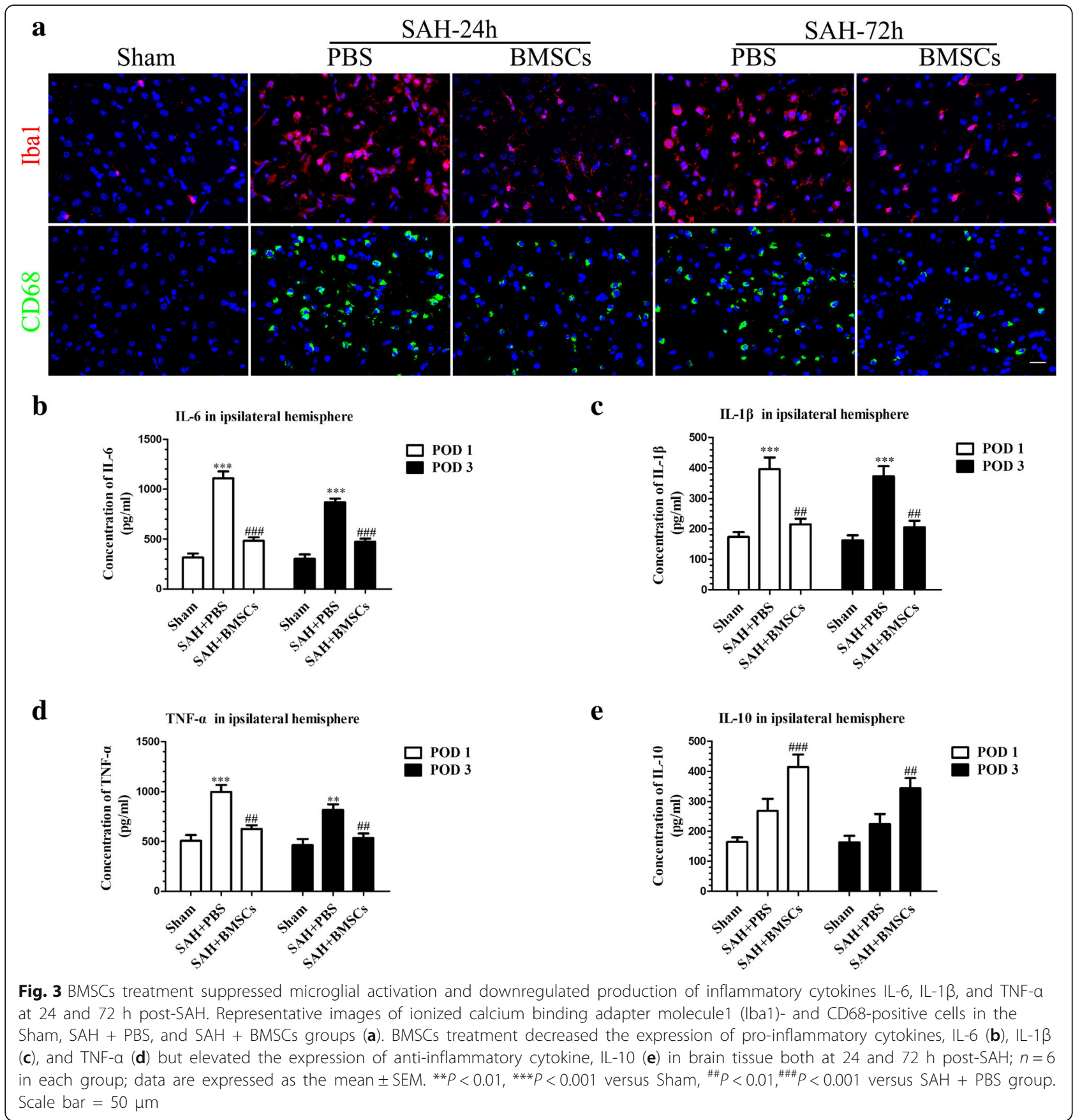

post-SAH, but these increases were negated after DAPT administration (Fig. 5g).

Administration of DAPT reduced NF-KB phosphorylation, the microglia activation, and inflammatory factor production at $24 \mathrm{~h}$ post-SAH

Notch1 activation enhances the microglia-mediated neuroinflammation following SAH through NF-kB phosphorylation. Western blotting analysis showed that NF-kB phosphorylation was noticeably increased after SAH and that DAPT administration significantly attenuated NF-kB phosphorylation (Additional file $3 \mathrm{~A}$ and $\mathrm{B}$ ). Consistent with the foregoing result, IF staining revealed activation of microglia (Fig. 6a) were markedly inhibited after DAPT administration. In addition, DAPT treatment decreased expression of inflammatory cytokines, IL-1 $\beta$, IL-6, and TNF- $\alpha$ (Fig. $6 b-d)$, but upregulated the anti-inflammatory cytokine, IL-10 (Fig. 6e), at $24 \mathrm{~h}$ post-SAH. 
$\mathbf{a}$

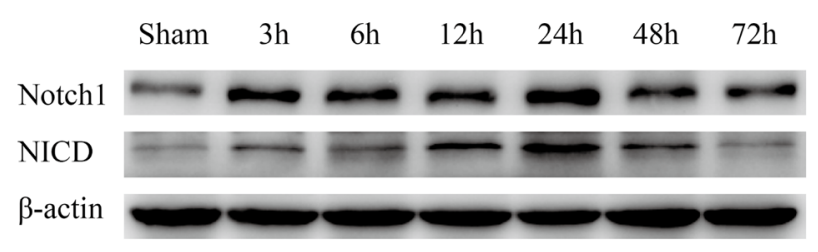

b

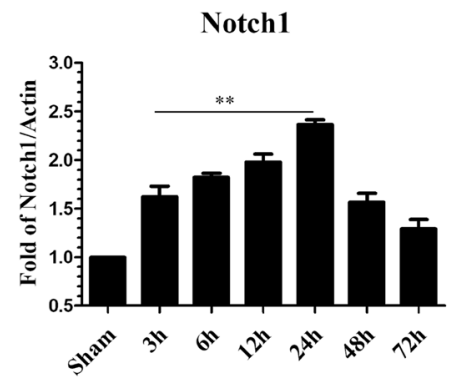

d

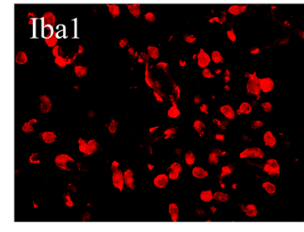

c

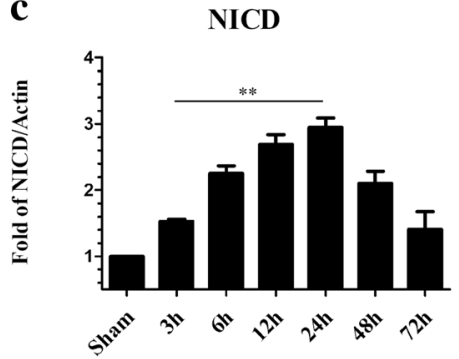

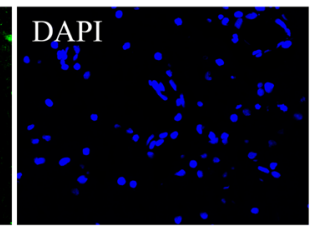

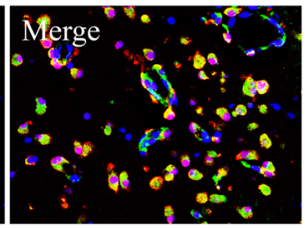

Fig. 4 Time course of Notch 1 and NICD expression in the left cortex after SAH. Representative images of Western blot data showing that endogenous Notch1 and NICD began to increase at $3 \mathrm{~h}$ and reached their highest expression at $24 \mathrm{~h}$ post-SAH (a). Quantification of Notch1 (b) and NICD (c) expression in the left cerebral cortex after SAH; $n=6$ in each group; data are expressed as the mean \pm SEM. ${ }^{* *} P<0.01$ versus Sham. Representative images of double immunofluorescence staining for NICD and Iba1 showing the co-localization of NICD with Iba1-positive microglia (d) in the left cerebral cortex at $24 \mathrm{~h}$ post-SAH. Scale bar $=50 \mu \mathrm{m}$. NICD Notch1 intracellular receptor domain

DAPT mitigates brain edema, neurodegeneration, and neurobehavioral deficits at $24 \mathrm{~h}$ post-SAH

To determine the protective function of DAPT at $24 \mathrm{~h}$ post-SAH, BWC, neurobehavioral deficits, and neurodegeneration were assessed. The results showed that DAPT significantly reduced BWC (Fig. 6f), improved neurobehavioral deficits (Fig. 6g), decreased the number of FJC-positive cells, and increased the number of NeuN-positive cells (Fig. 6h, i).

\section{Knockdown of Notch1 expression by RNA interference resulted in a reduction of Notch1 pathway-related molecules at $24 \mathrm{~h}$ post-SAH}

To confirm the functional implications of Notch1 activation after SAH, Notch1 siRNA was used to knockdown Notch1 expression in brain tissue. The efficiency of siRNA-mediated knockdown of Notch1 was confirmed by qRT-PCR (Fig. 7a).

Western blotting was performed to estimate the protein levels of Notch1 and its related pathway molecules, as shown in (Fig. 7b-f). Knockdown of Notch1 reduced Notch1, NICD, RBP-JK, and Hes-1 compared with the SAH + Scramble siRNA and SAH group. Furthermore, IF staining for NICD (Fig. 7g) and IHC staining for RBP-JK and Hes-1 (Fig. 7h) showed that NICD, RBP-JK, and Hes-1 were inhibited following knockdown of Notch1.

Notch1 knockdown inhibited NF-kB phosphorylation and reduced microglial activation and inflammatory cytokine infiltration at $24 \mathrm{~h}$ post-SAH

Phosphorylation of NF- $\mathrm{kB}$ was significantly increased at $24 \mathrm{~h}$ post-SAH, but Notch1 knockdown reduced this effect compared with SAH and SAH + Scramble siRNA groups (Additional file $3 \mathrm{C}$ and $\mathrm{D}$ ).

We next examined the effect of Notch1 knockdown on activated microglia. As shown in (Fig. 8a), Notch1 knockdown markedly suppressed Iba1- and CD68-positive cells at $24 \mathrm{~h}$ post-SAH. SAH-induced upregulation of pro-inflammatory cytokines IL-1 $\beta$, IL-6, and TNF- $\alpha$ were also reduced (Fig. $8 \mathrm{~b}-\mathrm{d}$ ), while the anti-inflammatory factor IL-10 was increased (Fig. 8e) following Notch1 knockdown.

Notch1 knockdown ameliorated neurodegeneration and improved neurobiological deficits and brain edema Notch1 knockdown markedly decreased BWC in cerebral tissue (Fig. 8f) and alleviated neurobiological deficits 


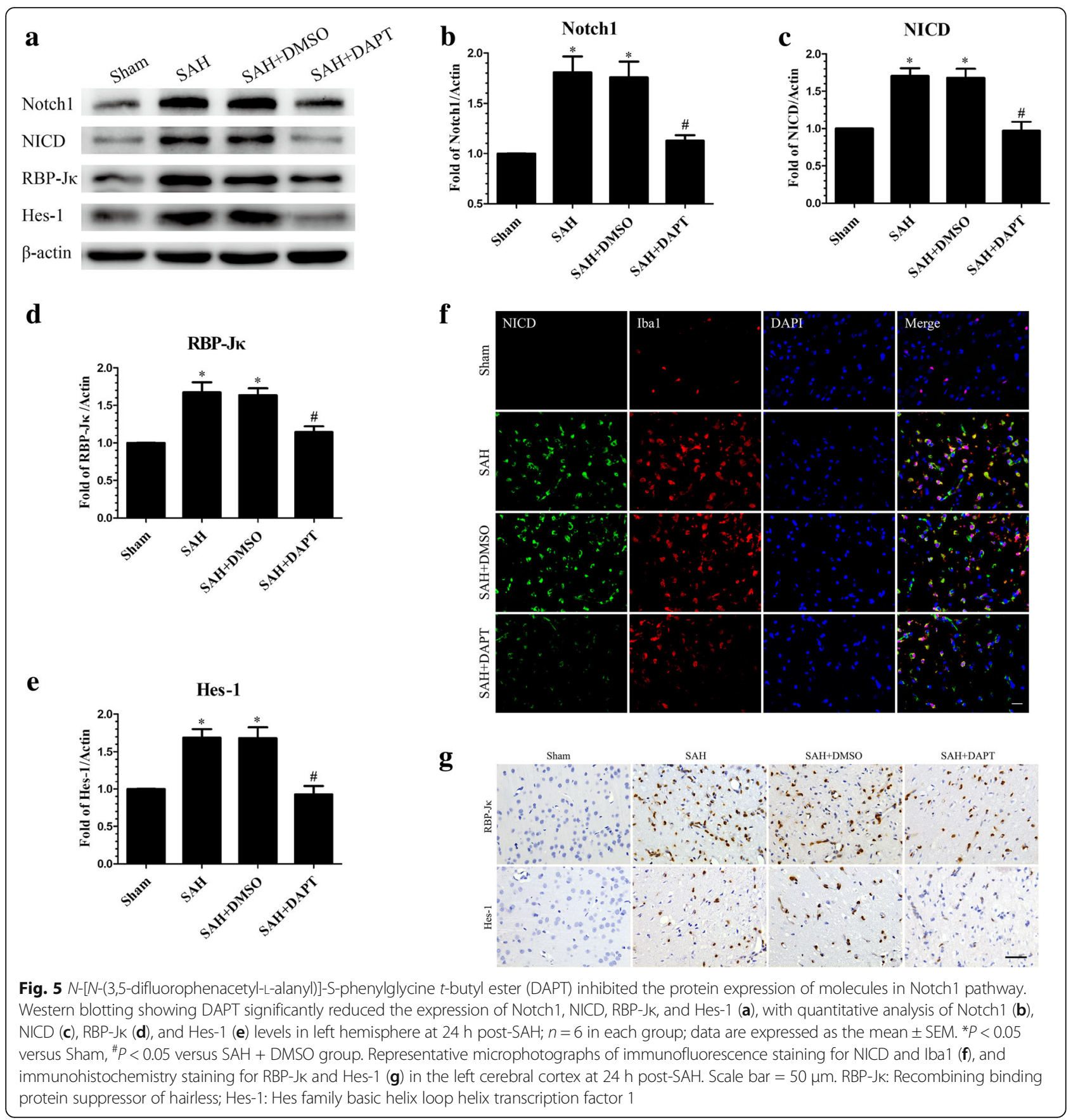

(Fig. 8g) compared with $\mathrm{SAH}$ and $\mathrm{SAH}+$ Scramble siRNA groups at $24 \mathrm{~h}$ post-SAH. The numbers of FJC-positive neurons were decreased (Fig. 8h, i) in the ipsilateral hemisphere after Notch1 siRNA injection, but the NeuN-positive neurons were increased.

\section{BMSCs treatment suppressed Notch1 signaling pathway} activation at $\mathbf{2 4} \mathrm{h}$ and $\mathbf{7 2} \mathrm{h}$ post-SAH

To explore the mechanisms involved in the protective effects of BMSCs on EBI after SAH, the expression of
Notch1 signaling pathway-associated factors was determined after BMSCs treatment at 24 and $72 \mathrm{~h}$ post-SAH. Western blotting results indicated that BMSCs treatment significantly inhibited the production of Notch1, NICD, RBP-JK, and Hes-1 (Fig. 9a-e) compared with the $\mathrm{SAH}+\mathrm{PBS}$ group. Consistent with the foregoing results, the mRNA levels of Notch1, RBP-JK, and Hes-1 were noticeably decreased after BMSCs treatment (Fig. 9f-h). IF staining showed that NICD immunofluorescence in activated microglia was reduced after BMSCs treatment 


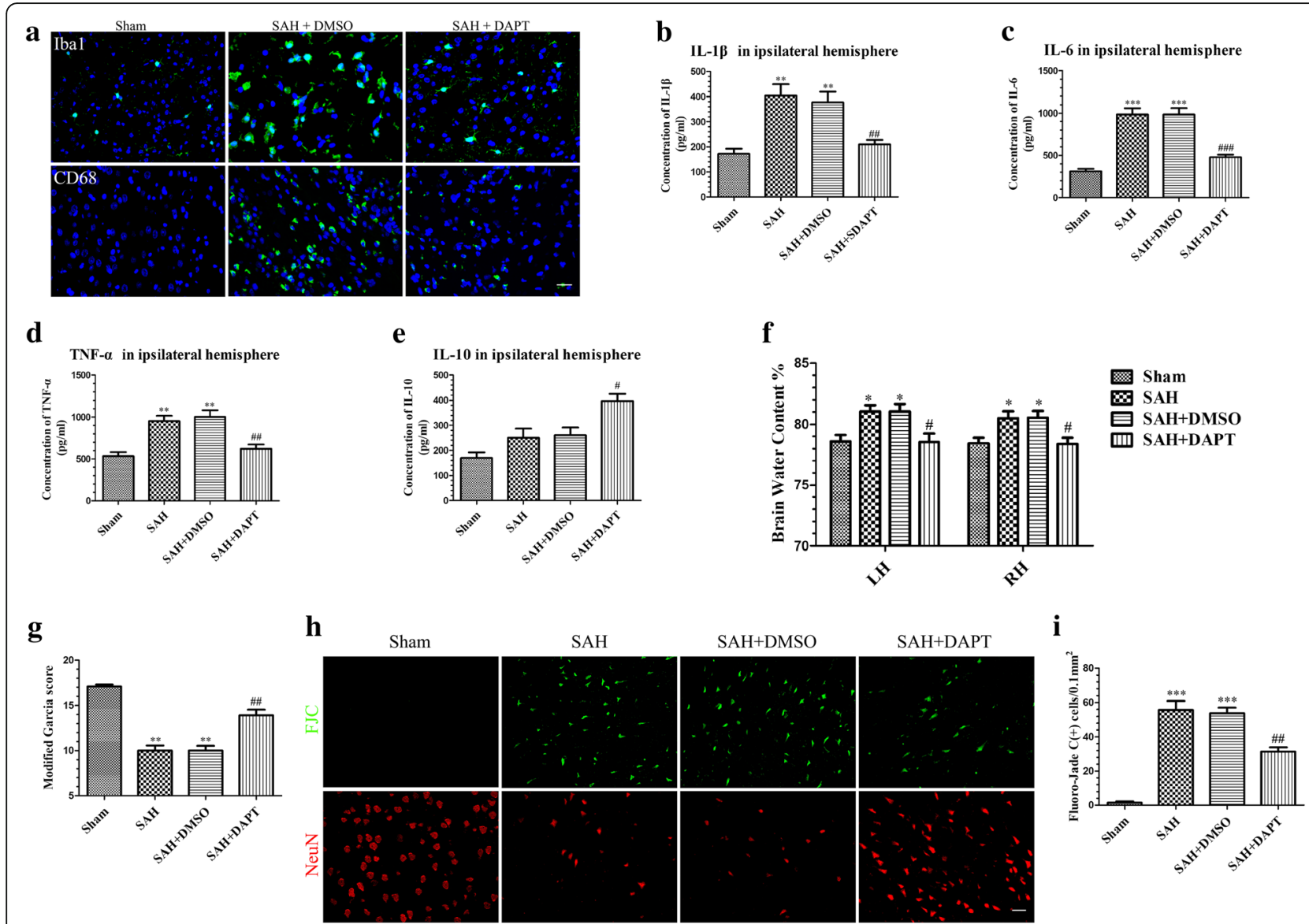

Fig. 6 Effects of DAPT on microglial activation, inflammatory factors production, brain edema, neurobehavioral deficits, and neuronal degeneration in SAH rats. Representative images of Iba1- and CD68-positive microglia in the Sham, SAH + DMSO, and SAH + DAPT groups (a). ELISA results indicating the levels of the pro-inflammatory factors IL-1 $\beta$ (b), IL-6 (c), and TNF- $\alpha(\mathbf{d})$ and the anti-inflammatory factor IL-10 (e) in the ipsilateral cerebral tissue at $24 \mathrm{~h}$ post-SAH; $n=6$ in each group. DAPT treatment markedly reduced BWC (f) $(n=6 /$ group) in the left hemisphere and increased modified Garcia score (g) ( $n=12$ /group). Representative FJC and NeuN staining images (h) and quantitative analysis of FJC-positive cells (i) $(n=6 / g r o u p)$ in the left cortex after SAH with DAPT or DMSO treatment. Data are expressed as the mean \pm SEM. ${ }^{*} P<0.05,{ }^{* *} P<0.01,{ }^{* * *} P<0.001$ versus Sham, ${ }^{\#} P<0.05,{ }^{\#} P<0.01, \# \# P 0.001$ versus $\mathrm{SAH}+$ DMSO group. Scale bar $=50 \mu \mathrm{m}$

(Fig. 9i). Finally, we also demonstrated that NF-kB phosphorylation after SAH was significantly inhibited following BMSCs treatment (Additional file 3E and F).

\section{Botch, an endogenous inhibitor of Notch1, was} significantly increased after BMSCs treatment at $24 \mathrm{~h}$ post-SAH

It has been reported that Botch can inhibit Notch signaling both in vitro and in vivo [47]. To confirm whether Botch participated in the protective effects of BMSCs on EBI after SAH, we examined the expression of Botch after SAH with and without BMSCs treatment. Results showed that protein and mRNA levels of Botch were upregulated at $24 \mathrm{~h}$ post-SAH compared with the sham group but not at $72 \mathrm{~h}$ post-SAH. BMSCs treatment significantly increased mRNA and protein levels of Botch compared with the SAH group (Fig. 10a-c).
Botch knockdown in BMSCs fully abolished the protective effects of BMSCs at $24 \mathrm{~h}$ post-SAH

To determine if Botch is required for EBI protection by BMSCs after SAH, we knocked down Botch expression in BMSCs. The qRT-PCR and Western blotting were performed to confirm that Botch expression in BMSCs was attenuated after knockdown with Botch shRNA (Fig. 11a-c). Botch knockdown BMSCs treatment abolished the effects of BMSCs on upregulation of Botch and inhibition of Notch1 levels at $24 \mathrm{~h}$ post-SAH (Fig. 11d-f). The attenuation of neurobehavioral deficits (Fig. 11g) and reduction in BWC (Fig. 11h) associated with BMSCs treatment was also negated following knockdown of Botch in BMSCs.

\section{Discussion}

In this study, we revealed that the beneficial effects of BMSCs on EBI and neuroinflammation after SAH may 

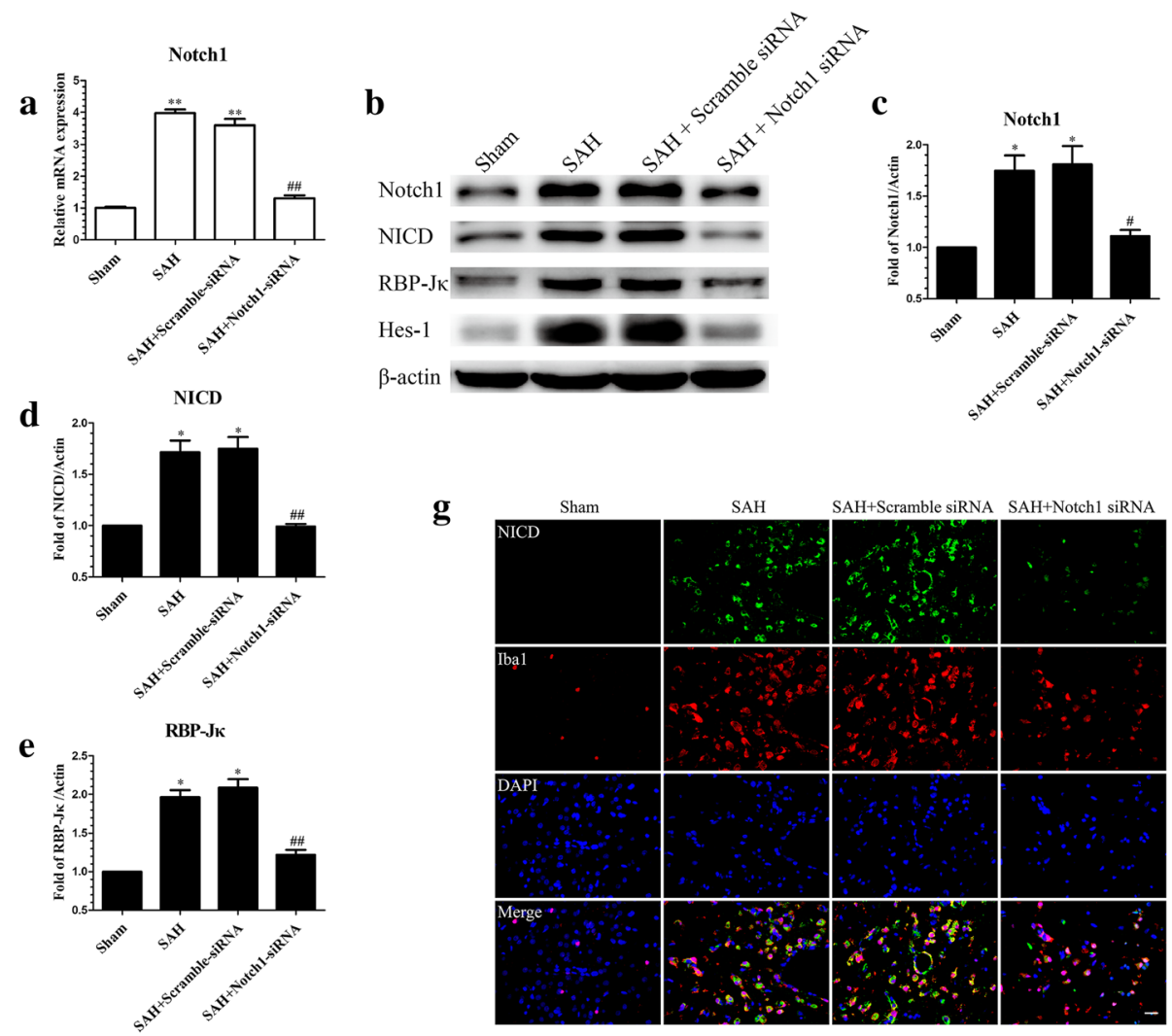

h
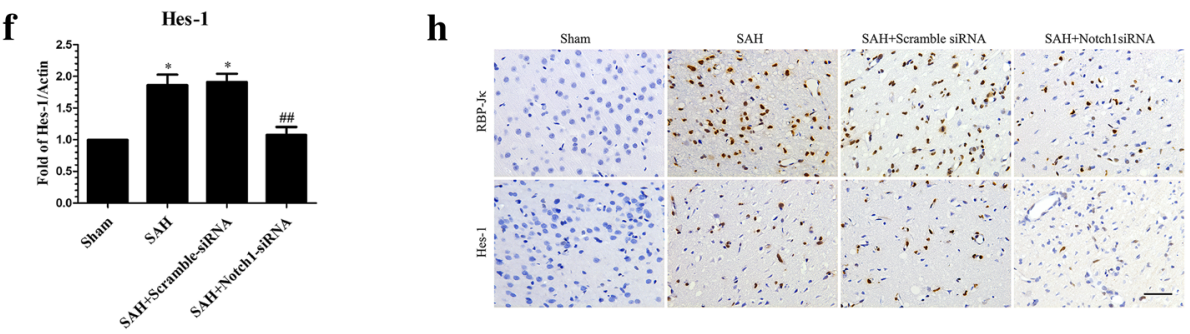

Fig. 7 Effects of Notch1 siRNA on the expression of molecules in the Notch1 pathway at $24 \mathrm{~h}$ post-SAH. The qRT-PCR analysis of the efficiency of siRNA-mediated knockdown of Notch1 in ipsilateral cerebral cortex (a); $n=3$ in each group; data are expressed as the mean \pm SEM ${ }^{* *} P<0.01$ versus Sham, ${ }^{\#} P<0.01$ versus SAH + Scramble siRNA group. The protein levels of Notch1 pathway-related agents were assessed by Western blot (b) and quantification of Notch1 (c), NICD (d), RBP-Jk (e), and Hes-1 (f) at 24 h post-SAH; $n=6$ in each group; data are expressed as the mean \pm SEM. ${ }^{*} P<0.05$ versus Sham, ${ }^{\#} P<0.05$, ${ }^{\# \#} P<0.01$ versus SAH + Scramble siRNA group. Representative images of NICD- and Iba1-positive cells (g) and immunohistochemistry staining for RBP-JK and Hes-1 (h) showing that Notch1 siRNA reduced the levels of NICD, RBP-JK and Hes-1 in ipsilateral cerebral cortex. Scale bar $=50 \mu \mathrm{m}$

be attributed to inhibition of Notch1-mediated microglial activation and neuronal degeneration by Botch. Our experiments demonstrated four important findings as follows: (1) BMSCs treatment improved neurobehavioral deficits, decreased the BWC, and ameliorated BBB disruption in EBI after SAH; (2) endogenous Notch1 expression was upregulated in a time-dependent manner and peaked at $24 \mathrm{~h}$ post-SAH. Inhibition of the Notch1 signaling pathway by DAPT or Notch1 siRNA suppressed activated microglia-mediated neuroinflammation and inhibited the expression of inflammatory factors, thereby ameliorating EBI after SAH; (3) BMSCs attenuated the inflammatory response at least partially due to inhibition of Notch1 signaling, which subsequently repressed NF-kB phosphorylation at 24 and $72 \mathrm{~h}$ post-SAH; and (4) shRNA-mediated knockdown of Botch in BMSCs reversed BMSCs-induced inhibition of Notch1 signaling and abolished the beneficial effects of BMSCs on EBI after SAH.

A growing body of clinical and preclinical studies suggests that the inflammatory response occurs early after $\mathrm{SAH}$ and contributes to the progression of $\mathrm{SAH}$-induced EBI [61-63]. As the resident immunocompetent and phagocytic cells of the CNS, activated microglia, which produce inflammatory mediators, play a significant role 


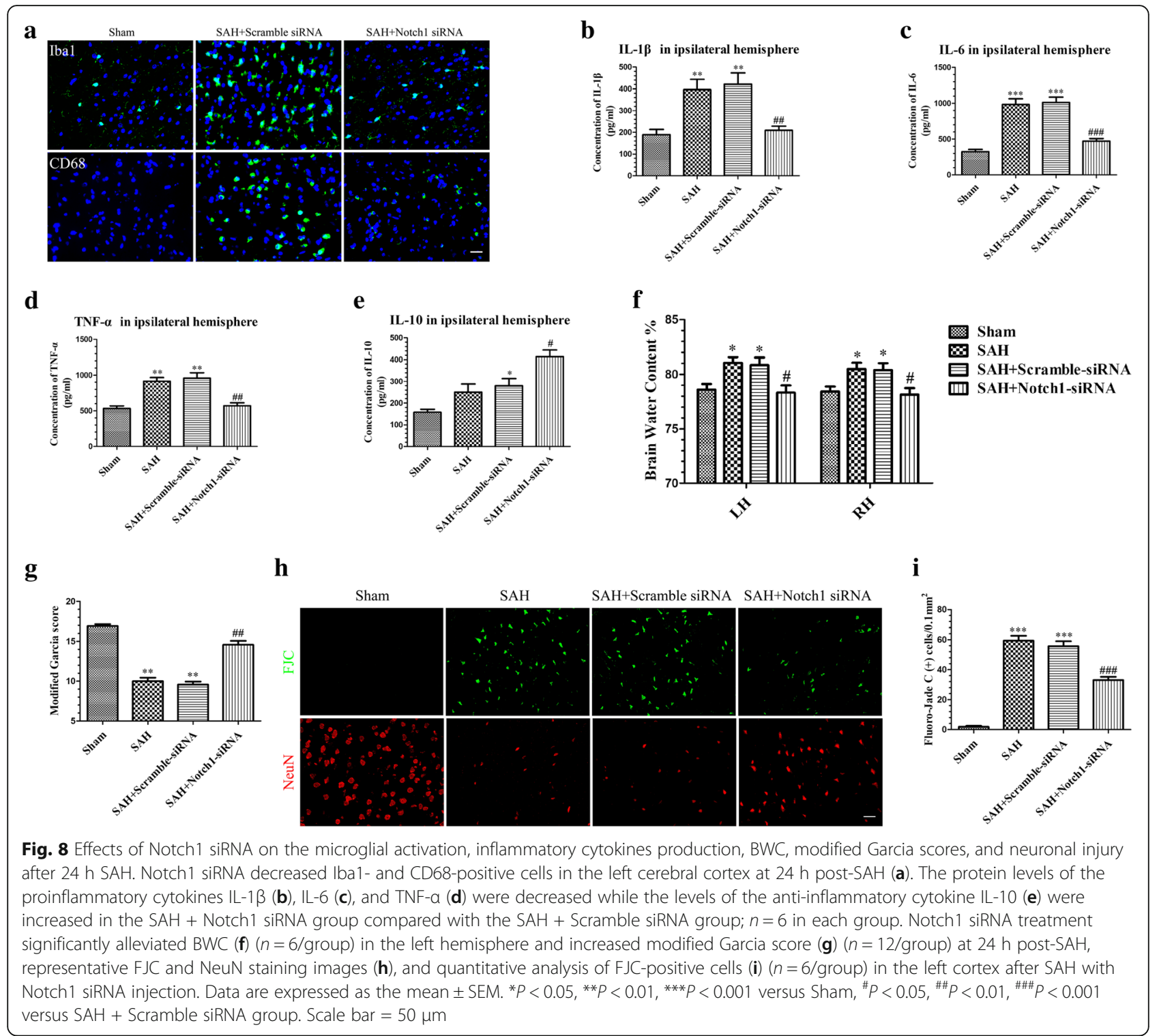

in neuroinflammation $[10,60]$. Thus, inhibition of microglial activation is beneficial to prevent deleterious inflammation and to alleviate inflammation-induced EBI after SAH [52].

In recent years, the beneficial effects of MSCs transplantation on various diseases had been attributed to parenchymal cell replacement, trophic factor secretion, and regulation of immunity [64-67]. BMSCs have been reported to ameliorate inflammation-induced brain injury in different CNS disease [14, 67-69] by suppressing microglial activation and inhibiting proinflammatory cytokines production. Consistent with these previous studies, our experimental results showed that BMSCs transplantation ameliorated brain edema, neurobehavioral deficits, and neuronal injury, as well as inhibited microglial activation; decreased the expression of proinflammatory factors including IL-6, IL-1 $\beta$, and TNF- $\alpha$; and increased the expression of the anti-inflammatory factor, IL-10, in EBI after SAH. Nevertheless, the underlying molecular mechanisms of the anti-inflammatory and neuroprotective functions of BMSCs on EBI needed further investigation.

Previous reports showed that Notch1 signaling exerted a critical role in the differentiation, proliferation, and apoptosis of cells during development and in adult tissues $[28,32]$. On binding to ligands, Notch1 is cleaved by furin-like convertase at the extracellular domain after which the transmembrane domain is incised by metalloproteases and the $\gamma$-secretase enzyme complex [70]; the NICD is translocated to the nucleus, where it regulates transcription of Notch1 target genes. Recent studies demonstrated that the Notch1 signaling pathway has an essential role in the regulation of the inflammatory 

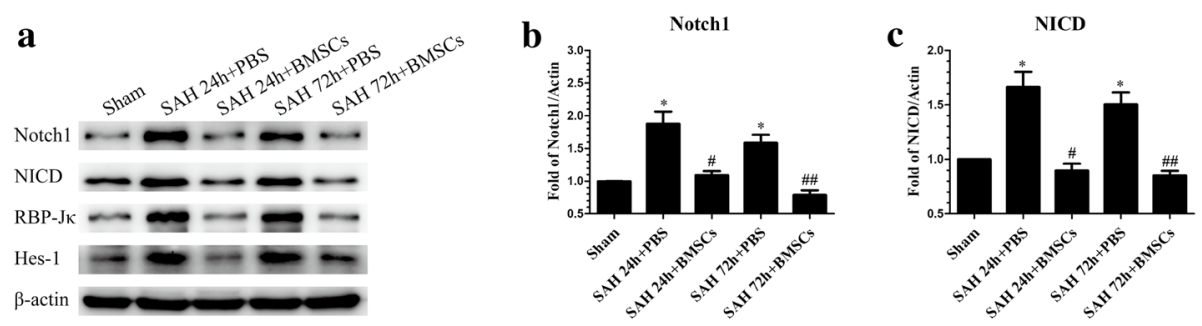

d

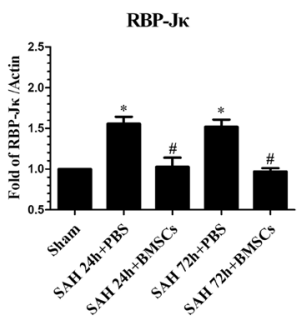

g

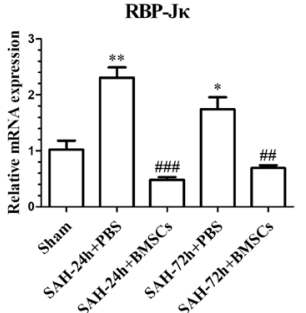

h

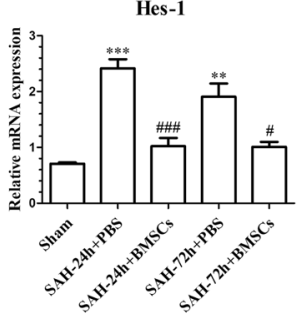

e

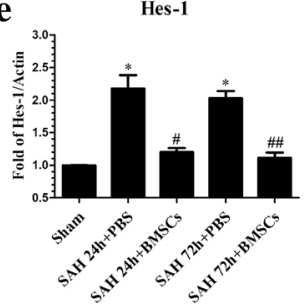

f

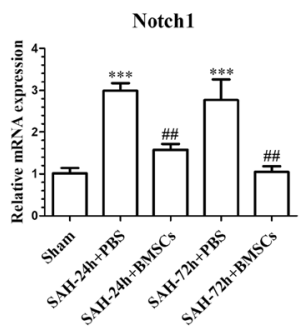

i

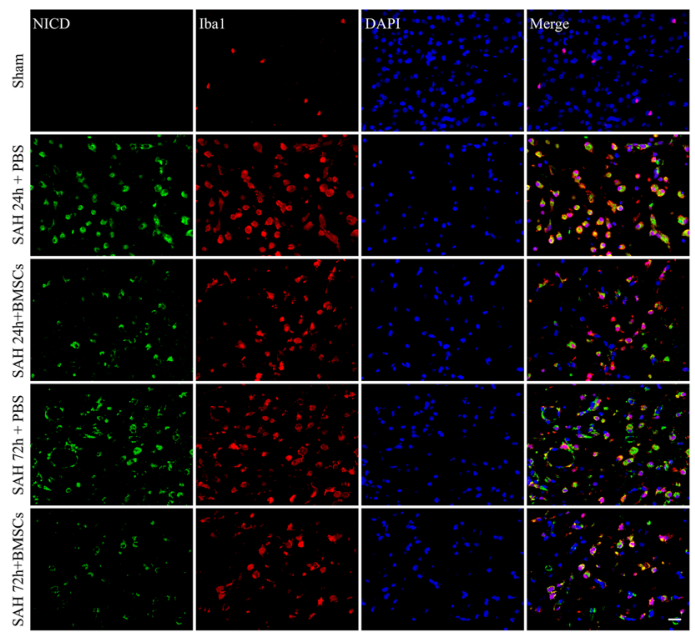

Fig. 9 BMSCs transplantation inhibited SAH-induced upregulation of the Notch1 pathway-related molecules, Notch1, NICD, RBP-JK, and Hes-1 at 24 and 72 h post-SAH. Representative image of Western blotting (a) and quantification of Notch1 (b), NICD (c), RBP-JK (d), and Hes-1 (e) protein levels after BMSCs treatment at 24 and $72 \mathrm{~h}$ post-SAH; $n=6$ in each group; data are expressed as the mean \pm SEM. ${ }^{*} P<0.05$ versus Sham, ${ }^{\#} P<0.05,{ }^{\# \#} P<0.01$ versus SAH+PBS group. The qRT-PCR analysis of Notch 1 (f), RBP-Jk (g), and Hes-1 (h) mRNA levels at 24 and $72 \mathrm{~h}$ post-SAH; $n=3$ in each group; data are expressed as the mean \pm SEM. ${ }^{*} P<0.05,{ }^{* *} P<0.01,{ }^{* * *} P<0.001$ versus Sham, ${ }^{\#} P<0.05$, ${ }^{\# \#} P<0.01$, ${ }^{\# \#} P<0.001$ versus SAH + PBS group. Typical images of double-immunofluorescence staining for NICD and Iba1 (i) showing that BMSCs treatment suppressed NICD expression in Iba1-positive microglia at 24 and $72 \mathrm{~h}$ post-SAH. Scale bar $=50 \mu \mathrm{m}$

response in different pathological settings [34, 35, 71, 72]. In the CNS, Notch 1 signaling not only regulates microglia-mediated neuroinflammation [36-38] but also participates in the process of neuronal injury in ischemic stroke [40]. Our study revealed that Notch1 expression was significantly increased and peaked at $24 \mathrm{~h}$ post-SAH and that the NICD was primarily localized in microglia. Based on these results, we speculated that Notch1 signaling pathway activation possibly enhanced microglial activation, thus upregulating proinflammatory cytokines, which may have exacerbated EBI after SAH. DAPT, as a $\gamma$-secretase inhibitor, can suppress Notch1 signaling activation, with several studies demonstrating that DAPT ameliorated brain damage and neurological deficits and inhibited proinflammatory cytokine secretion and microglial activation in an ischemic stroke model [39, 41]. Consistent with the above findings, our results showed that DAPT administration significantly inhibited the expression of Notch1 and its downstream factors, including Notch1, NICD, RBP-JK, and Hes-1 compared with SAH + DMSO group after SAH. DAPT treatment also suppressed the microglia-mediated inflammatory reaction, alleviated brain edema and neuronal injury, and improved neurobiological deficits at $24 \mathrm{~h}$ post-SAH.

Recent studies reported that Notch1 enhanced the inflammatory reaction $[35,41]$ and aggravated the neuronal degeneration [40], at least in part, by augmenting NF- $\mathrm{kB}$ phosphorylation; our results indicated that the 


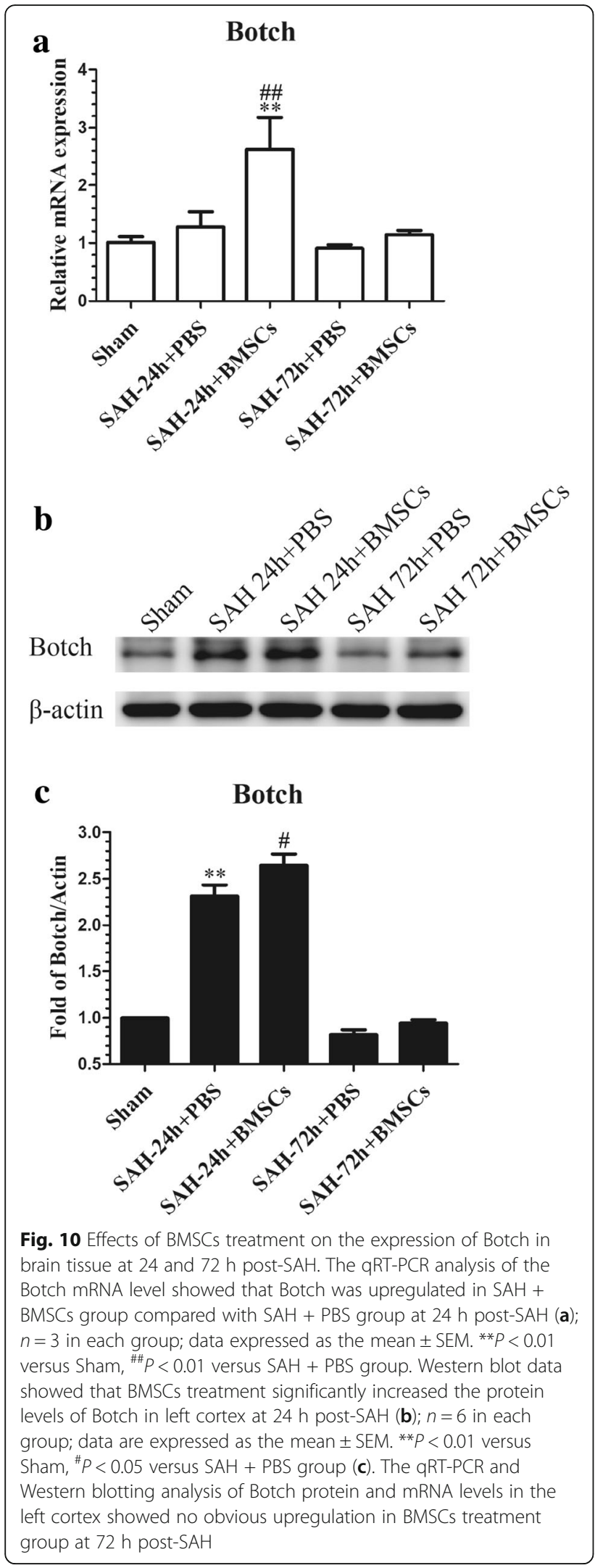

increased expression of phosphorylated NF- $\mathrm{B} B$ after $\mathrm{SAH}$ was suppressed after DAPT treatment. In addition, we used Notch1 siRNA to confirm the functions of Notch1 signaling in the microglia-mediated inflammatory response in EBI after SAH. Our data showed that Notch1 siRNA successfully knocked down the expression of Notch1 signaling and decreased microglial activation and neuronal degeneration; as well as ameliorated cerebral edema and neurobehavioral deficits. Protein levels of p-NF- $\mathrm{kB}$ were also reduced after Notch1 knockdown $48 \mathrm{~h}$ prior to $\mathrm{SAH}$. Based on these results, we speculate that Notch1 signaling may participate in the neuroinflammatory reaction and brain injury in EBI after $\mathrm{SAH}$ by regulating the phosphorylation of NF- $\mathrm{kB}$.

It has been reported that BMSCs transplantation enhanced neurogenesis after ischemic stroke [42] and improved osteopenia in Lupus [44] via inhibiting Notch1 signaling. We therefore speculated that BMSCs treatment alleviated microglia-mediated neuroinflammation and neuronal injury in EBI after SAH partly by inhibition of the Notch1 signaling pathway. In the present study, our findings showed that Notch1 signaling was significantly suppressed by BMSCs at $24 \mathrm{~h}$ and $72 \mathrm{~h}$ post-SAH, which was confirmed by measuring protein and mRNA levels of Notch1, NICD, RBP-JK, and Hes-1. Double immunofluorescence staining also revealed that the expression of NICD in activated microglia was decreased after BMSCs treatment. Additionally the expression of $\mathrm{p}-\mathrm{NF}-\mathrm{kB}$ was significantly inhibited after BMSCs administration. Taken together, these results indicated that BMSCs may ameliorate neuroinflammation in EBI after SAH through inhibition of Notch1 signaling and NF- $\mathrm{kB}$ phosphorylation.

Previous study demonstrated that overexpression of Botch in vivo alleviated neuronal apoptosis and inflammation in intracerebral hemorrhage [48]. We hypothesized that BMSCs transplantation inhibited Notch1 signaling by increasing Botch expression in brain tissue; we first detected Botch protein and mRNA levels in BMSCs, with results indicating that Botch strongly expressed in cultured BMSCs. Then we detected levels of Botch expression after $\mathrm{SAH}$ with and without BMSCs treatment, and showed that Botch expression was slightly increased compared with the sham group and that BMSCs treatment significantly increased the expression of Botch in the ipsilateral hemisphere. Finally, we knocked down Botch in BMSCs and administrated these cells intravenously after SAH. The results indicated that knockdown of Botch in BMSCs abrogated beneficial effects of BMSCs on EBI after SAH and that the inhibition of Notch1 signaling was also abolished. These results suggested that the neuroprotective and anti-inflammatory effects of BMSCs were partly attributed to the upregulation of Botch expression which resulted in suppression of the Notch1 signaling pathway. 


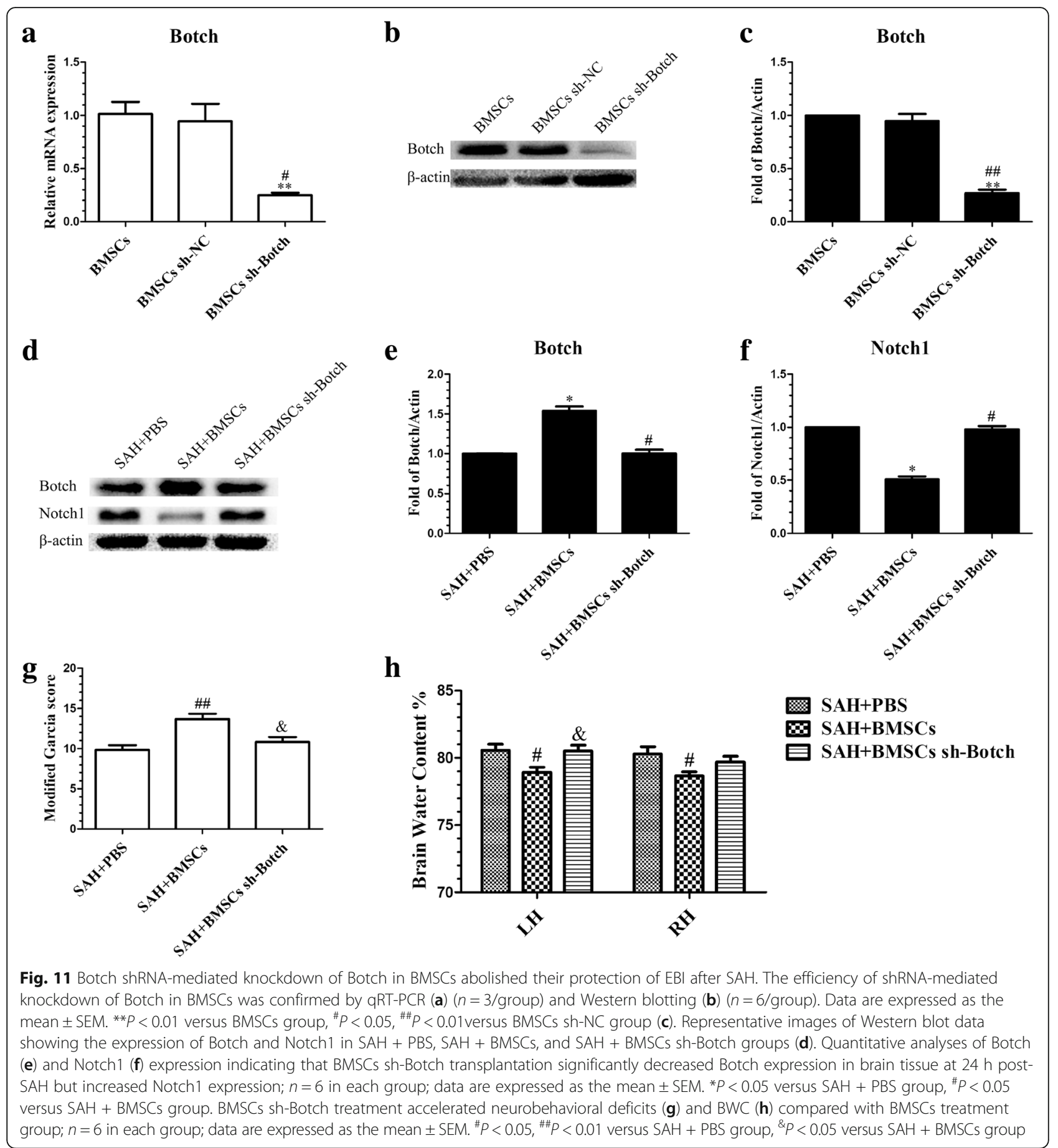

There are several points in our study that need to be discussed. First, although EBI as a new pathological mechanism has been explored in recent years, cerebral vasospasm remains a cause of morbidity and mortality after aneurismal SAH. Previous studies suggested that BMSCs transplantation exerted other protective functions, such as promote angiogenesis, prevent endothelial damage, and enlarge the diameters of the basilar artery and pial vessels via differentiating into endothelial cells and secreting functional molecules in ischemic stroke [72-74]; our study only investigated the anti-inflammatory effects of BMSCs on EBI after SAH, therefore we cannot rule out the possible vascular effects of BMSCs on cerebral vasospasm-mediated ischemic injury after SAH. Second, only an immediate post-SAH intravenous injection of BMSCs was tested; the effects of multiple systemic BMSCs treatment at different time course on long-term outcome should be examined. Finally, further experiments of 
BMSCs treatment combined with Notch1 agonists and inhibitors should be performed to better demonstrate that BMSC treatment alleviated neurobehavioral impairments and the inflammatory response in EBI after SAH via upregulation of Botch to suppress Notch1 signaling.

\section{Conclusions}

This study demonstrated that the neuroprotective effects of BMSCs in the treatment of EBI after SAH were partly due to Botch upregulation in brain tissue, which inhibited Notch1 signaling-induced NF- $\mathrm{kB}$ phosphorylation and then alleviated microglia-mediated neuroinflammation (Additional file 1). Therefore, BMSCs transplantation may provide a promising therapeutic method against EBI after SAH.

\section{Additional files}

Additional file 1: The experimental design and schematic diagram. Six experiments were conducted in our study. The schematic diagram showed the potential mechanism of BMSCs mediated anti-inflammatory effects on EBI after SAH. Briefly, Notch1 receptors are expressed on microglial cells. Following SAH ictus, Notch1 is activated by proteolytic cleavage, thus releasing NICD into the cytoplasm, which in turn enhances NF-KB activation. In addition, NICD can translocate to the nucleus and combine with RBP-JK to generate co-activator complex to promote the transcription of NF-KB and augment the inflammatory response. Botch efficiently antagonized the proteolytic cleavage and activation of the Notch1 receptor. BMSCs treatment upregulated Botch in brain tissue and alleviated the Notch1-driven microglia-mediated inflammatory response. (PDF $88 \mathrm{~kb}$ )

Additional file 2: Co-staining of NeuN and CD68 as well as NueN and Ibal at $24 \mathrm{~h}$ post-SAH. Representative images of double immunofluorescence staining for NeuN and CD68 or lba1, results showed that Iba1- and CD68-positive cells were increased, but the numbers of NeuN-positive neurons were decreased in the cortex of left hemisphere after $24 \mathrm{~h} \mathrm{SAH}$. (TIF $8397 \mathrm{~kb}$ )

Additional file 3: Effects of DAPT, Notch1 siRNA and BMSCs on (Nuclear factor-kB) NF-kB phosphorylation after SAH. DAPT administration inhibited $\mathrm{p}-\mathrm{NF}-\mathrm{kB}$ expression at $24 \mathrm{~h}$ post-SAH. Representative western blot bands ( $\mathrm{A}$ ) and quantification of $\mathrm{p}-\mathrm{NF}-\mathrm{kB}$ in the left cortex (B) indicate that DAPT inhibited NF-KB phosphorylation at $24 \mathrm{~h}$ post-SAH; $n=6$ in each group; data are expressed as the mean \pm SEM. ${ }^{*} P<0.05$ versus Sham, $\# \# P<0.001$ versus SAH + DMSO group. Notch1 siRNA injection inhibited phosphorylation of NF-KB at $24 \mathrm{~h}$ post-SAH. Representative western blot bands (C) and quantitative analyses of p-NF-kB expression in the left cortex (D) show that knockdown Notch1 inhibited NF-KB phosphorylation at $24 \mathrm{~h}$ post-SAH; $n=6$ in each group; data are expressed as the mean \pm SEM. ${ }^{*} P<0.05$ versus Sham, ${ }^{\# \# \#} P<0.001$ versus $\mathrm{SAH}+$ Scramble siRNA group. BMSCs treatment suppressed NF-KB phosphorylation at 24 and $72 \mathrm{~h}$ post$\mathrm{SAH}$. Western blot data showed that BMSCs significantly suppressed the phosphorylation of NF-KB ( $E$ and $F$ ) at 24 and $72 \mathrm{~h}$ post-SAH; $n=6$ in each group; data are expressed as the mean \pm SEM. ${ }^{*} P<0.05$ versus Sham, ${ }^{\#} P<0.05$ versus $S A H+$ PBS group. (TIF $4601 \mathrm{~kb}$ )

\section{Abbreviations}

ANOVA: Analysis of variance; BBB: Blood-brain barrier; BMSCs: Bone marrow mesenchymal stem cells; BWC: Brain water content; CD: Cluster of differentiation; Chac1: Cation transport regulator homolog 1; CNS: Central nervous system; DAPT: $N$-[N-(3,5-difluorophenacetyl-L-alanyl)]-S-phenylglycine t-butyl ester; DMSO: Dimethylsulfoxide; DW: Dry weight; EBI: Early brain injury; ECA: External carotid artery; ELISA: Enzyme-linked immunosorbent assay; FJC: Fluoro-Jade C; H\&E: Hematoxylin and eosin; Hes-1: Hes family basic helix loop helix transcription factor 1; Iba1: lonized calcium binding adapter molecule1; ICA: Internal carotid artery; IF: Immunofluorescence; IHC: Immunohistochemistry; IL: Interleukin; MRI: Magnetic resonance imaging; MSCs: Mesenchymal stem cells; NC: Negative control; NF-kB: Nuclear factorKB; NICD: Notch1 intracellular receptor domain; NPG7: Neuroprotective gene 7; PBS: Phosphate buffer solution; P-NF-KB: Phosphorylation of nuclear factorKB; qRT-PCR: Quantitative real-time polymerase chain reaction; RBP$J_{\mathrm{K}}$ : Recombining binding protein suppressor of hairless; RT: Room temperature; SAH: Subarachnoid hemorrhage; SEM: Standard error of the mean; shRNA: Short hairpin RNA; siRNA: Small interfering RNA; TE: Echo time; TNF: Tumor necrosis factor; TR: Repetition time; WW: Wet weight

\section{Acknowledgements}

Not applicable.

\section{Funding}

This study was supported by Science and Technology Project Foundation of Guangdong province (Grant number 2016A020215098), Key Project of Clinical Research of Southern Medical University (Grant number LC2016ZD024), the National Key Research Development Program (Grant number 2016YFC1300804, 2016YFC1300800), and Guangdong Provincial Clinical Medical Centre for Neurosurgery (Grant number 2013B020400005).

\section{Availability of data and materials}

The datasets used and/or analyzed during the current study are available from the corresponding author on reasonable request.

\section{Authors' contributions}

WCL, XFL, XYH, and CZD contributed to the conception and design. RL, JY, SQG WCL, and ZJL performed the main part of the experiments. YCC and HYF participated in the acquisition and analysis of data. XZ and GCL wrote the manuscript and supervised the study. All authors critically reviewed and approved the submitted version of the manuscript.

\section{Ethics approval and consent to participate}

All experimental procedures were approved by the Southern Medical University Ethics Committee and were performed in accordance with the guidelines of the National Institutes of Health on the care and use of animals.

\section{Consent for publication}

Not applicable.

\section{Competing interests}

The authors declare that they have no competing interests.

\section{Publisher's Note}

Springer Nature remains neutral with regard to jurisdictional claims in published maps and institutional affiliations.

Received: 9 July 2018 Accepted: 2 January 2019

Published online: 15 January 2019

\section{References}

1. Biller J, Godersky JC, Adams HJ. Management of aneurysmal subarachnoid hemorrhage. Stroke. 1988;19:1300-5.

2. Schievink Wl, Riedinger M, Jhutty TK, Simon P. Racial disparities in subarachnoid hemorrhage mortality: Los Angeles County, California, 19851998. Neuroepidemiology. 2004;23:299-305.

3. Crowley RW, Medel R, Kassell NF, Dumont AS. New insights into the causes and therapy of cerebral vasospasm following subarachnoid hemorrhage. Drug Discov Today. 2008;13:254-60.

4. Macdonald RL, Higashida RT, Keller E, Mayer SA, Molyneux A, Raabe A, Vajkoczy P, Wanke I, Bach D, Frey A, et al. Clazosentan, an endothelin receptor antagonist, in patients with aneurysmal subarachnoid haemorrhage undergoing surgical clipping: a randomised, double-blind, placebo-controlled phase 3 trial (CONSCIOUS-2). Lancet Neurol. 2011;10: 618-25.

5. Macdonald RL, Higashida RT, Keller E, Mayer SA, Molyneux A, Raabe A, Vajkoczy P, Wanke I, Bach D, Frey A, et al. Randomized trial of clazosentan in patients with aneurysmal subarachnoid hemorrhage undergoing endovascular coiling. Stroke. 2012;43:1463-9. 
6. Vergouwen MD, llodigwe D, Macdonald RL. Cerebral infarction after subarachnoid hemorrhage contributes to poor outcome by vasospasmdependent and -independent effects. Stroke. 2011;42:924-9.

7. Chen S, Feng H, Sherchan P, Klebe D, Zhao G, Sun X, Zhang J, Tang J, Zhang JH. Controversies and evolving new mechanisms in subarachnoid hemorrhage. Prog Neurobiol. 2014;115:64-91.

8. Friedrich V, Flores R, Muller A, Bi W, Peerschke El, Sehba FA. Reduction of neutrophil activity decreases early microvascular injury after subarachnoid haemorrhage. J Neuroinflammation. 2011;8:103.

9. Chen S, Ma Q, Krafft PR, Hu Q, Rolland WN, Sherchan P, Zhang J, Tang J, Zhang JH. P2X7R/cryopyrin inflammasome axis inhibition reduces neuroinflammation after SAH. Neurobiol Dis. 2013;58:296-307.

10. Xu H, Li J, Wang Z, Feng M, Shen Y, Cao S, Li T, Peng Y, Fan L, Chen J, et al. Methylene blue attenuates neuroinflammation after subarachnoid hemorrhage in rats through the Akt/GSK-3beta/MEF2D signaling pathway. Brain Behav Immun. 2017;65:125-39.

11. Provencio JJ, Swank V, Lu H, Brunet S, Baltan S, Khapre RV, Seerapu H, Kokiko-Cochran ON, Lamb BT, Ransohoff RM. Neutrophil depletion after subarachnoid hemorrhage improves memory via NMDA receptors. Brain Behav Immun. 2016;54:233-42.

12. Yoo SW, Chang DY, Lee HS, Kim GH, Park JS, Ryu BY, Joe EH, Lee YD, Kim SS, Suh-Kim H. Immune following suppression mesenchymal stem cell transplantation in the ischemic brain is mediated by TGF-beta. Neurobiol Dis. 2013;58:249-57.

13. Sheikh AM, Nagai A, Wakabayashi K, Narantuya D, Kobayashi S, Yamaguchi S, Kim SU. Mesenchymal stem cell transplantation modulates neuroinflammation in focal cerebral ischemia: contribution of fractalkine and IL-5. Neurobiol Dis. 2011;41:717-24.

14. Drommelschmidt K, Serdar M, Bendix I, Herz J, Bertling F, Prager S, Keller M, Ludwig AK, Duhan V, Radtke S, et al. Mesenchymal stem cell-derived extracellular vesicles ameliorate inflammation-induced preterm brain injury. Brain Behav Immun. 2017;60:220-32.

15. Gerdoni E, Gallo B, Casazza S, Musio S, Bonanni I, Pedemonte E, Mantegazza R, Frassoni F, Mancardi G, Pedotti R, Uccelli A. Mesenchymal stem cells effectively modulate pathogenic immune response in experimental autoimmune encephalomyelitis. Ann Neurol. 2007;61:219-27.

16. Orack JC, Deleidi M, Pitt D, Mahajan K, Nicholas JA, Boster AL, Racke MK, Comabella M, Watanabe F, Imitola J. Concise review: modeling multiple sclerosis with stem cell biological platforms: toward functional validation of cellular and molecular phenotypes in inflammation-induced neurodegeneration. Stem Cells Transl Med. 2015;4:252-60.

17. Williams AR, Hare JM. Mesenchymal stem cells: biology, pathophysiology, translational findings, and therapeutic implications for cardiac disease. Circ Res. 2011;109:923-40.

18. Zhang R, Liu Y, Yan K, Chen L, Chen XR, Li P, Chen FF, Jiang XD. Antiinflammatory and immunomodulatory mechanisms of mesenchymal stem cell transplantation in experimental traumatic brain injury. J Neuroinflammation. 2013;10:106.

19. Bianco P, Cao X, Frenette PS, Mao JJ, Robey PG, Simmons PJ, Wang CY. The meaning, the sense and the significance: translating the science of mesenchymal stem cells into medicine. Nat Med. 2013;19:35-42

20. Wang Y, Chen X, Cao W, Shi Y. Plasticity of mesenchymal stem cells in immunomodulation: pathological and therapeutic implications. Nat Immunol. 2014;15:1009-16.

21. Gnecchi M, He H, Liang OD, Melo LG, Morello F, Mu H, Noiseux N, Zhang L, Pratt RE, Ingwall JS, Dzau VJ. Paracrine action accounts for marked protection of ischemic heart by Akt-modified mesenchymal stem cells. Nat Med. 2005;11:367-8.

22. Lee RH, Pulin AA, Seo MJ, Kota DJ, Ylostalo J, Larson BL, Semprun-Prieto L, Delafontaine P, Prockop DJ. Intravenous hMSCs improve myocardial infarction in mice because cells embolized in lung are activated to secrete the anti-inflammatory protein TSG-6. Cell Stem Cell. 2009:5:54-63.

23. Hegyi B, Kornyei Z, Ferenczi S, Fekete R, Kudlik G, Kovacs KJ, Madarasz E, Uher F. Regulation of mouse microglia activation and effector functions by bone marrow-derived mesenchymal stem cells. Stem Cells Dev. 2014;23: 2600-12.

24. Zhou C, Zhang C, Zhao R, Chi S, Ge P, Zhang C. Human marrow stromal cells reduce microglial activation to protect motor neurons in a transgenic mouse model of amyotrophic lateral sclerosis. J Neuroinflammation. 2013;10:52.

25. Khalili MA, Anvari M, Hekmati-Moghadam SH, Sadeghian-Nodoushan F, Fesahat F, Miresmaeili SM. Therapeutic benefit of intravenous transplantation of mesenchymal stem cells after experimental subarachnoid hemorrhage in rats. J Stroke Cerebrovasc Dis. 2012;21:445-51.

26. Khalili MA, Sadeghian-Nodoushan F, Fesahat F, Mir-Esmaeili SM, Anvari M, Hekmati-Moghadam SH. Mesenchymal stem cells improved the ultrastructural morphology of cerebral tissues after subarachnoid hemorrhage in rats. Exp Neurobiol. 2014;23:77-85.

27. Nijboer $\mathrm{CH}$, Kooijman E, van Velthoven $\mathrm{CT}$, van Tilborg E, Tiebosch IA, Eijkelkamp N, Dijkhuizen RM, Kesecioglu J, Heijnen CJ. Intranasal stem cell treatment as a novel therapy for subarachnoid hemorrhage. Stem Cells Dev. 2018:27:313-25.

28. Artavanis-Tsakonas S, Rand MD, Lake RJ. Notch signaling: cell fate control and signal integration in development. Science. 1999;284:770-6.

29. Selkoe D, Kopan R. Notch and Presenilin: regulated intramembrane proteolysis links development and degeneration. Annu Rev Neurosci. 2003; 26:565-97.

30. Kopan R. Notch: a membrane-bound transcription factor. J Cell Sci. 2002; 115:1095-7.

31. Kramer H. RIPping notch apart: a new role for endocytosis in signal transduction? Sci STKE. 2000;2000:e1.

32. Kopan R, llagan MX. The canonical notch signaling pathway: unfolding the activation mechanism. Cell. 2009;137:216-33.

33. Lutolf $S$, Radtke F, Aguet M, Suter $U$, Taylor V. Notch1 is required for neuronal and glial differentiation in the cerebellum. Development. 2002;129: 373-85.

34. Piggott K, Deng J, Warrington K, Younge B, Kubo JT, Desai M, Goronzy JJ, Weyand CM. Blocking the NOTCH pathway inhibits vascular inflammation in large-vessel vasculitis. Circulation. 2011;123:309-18.

35. Zeng Q, Jin C, Ao L, Cleveland JJ, Song R, Xu D, Fullerton DA, Meng X. Cross-talk between the toll-like receptor 4 and Notch1 pathways augments the inflammatory response in the interstitial cells of stenotic human aortic valves. Circulation. 2012;126:S222-30.

36. Wei Z, Chigurupati S, Arumugam TV, Jo DG, Li H, Chan SL. Notch activation enhances the microglia-mediated inflammatory response associated with focal cerebral ischemia. Stroke. 2011:42:2589-94.

37. Yuan $Y$, Rangarajan $P$, Kan EM, Wu Y, Wu C, Ling EA. Scutellarin regulates the notch pathway and affects the migration and morphological transformation of activated microglia in experimentally induced cerebral ischemia in rats and in activated BV-2 microglia. J Neuroinflammation. 2015;12:11.

38. Cao Q, Lu J, Kaur C, Sivakumar V, Li F, Cheah PS, Dheen ST, Ling EA. Expression of Notch-1 receptor and its ligands Jagged-1 and Delta-1 in amoeboid microglia in postnatal rat brain and murine BV-2 cells. Glia. 2008; 56:1224-37.

39. Arumugam TV, Chan SL, Jo DG, Yilmaz G, Tang SC, Cheng A, Gleichmann M, Okun E, Dixit VD, Chigurupati S, et al. Gamma secretase-mediated notch signaling worsens brain damage and functional outcome in ischemic stroke. Nat Med. 2006;12:621-3.

40. Arumugam TV, Cheng YL, Choi Y, Choi YH, Yang S, Yun YK, Park JS, Yang DK, Thundyil J, Gelderblom M, et al. Evidence that gamma-secretasemediated notch signaling induces neuronal cell death via the nuclear factor-kappaB-Bcl-2-interacting mediator of cell death pathway in ischemic stroke. Mol Pharmacol. 2011;80:23-31.

41. Yao L, Kan EM, Kaur C, Dheen ST, Hao A, Lu J, Ling EA. Notch-1 signaling regulates microglia activation via NF-kappaB pathway after hypoxic exposure in vivo and in vitro. PLoS One. 2013;8:e78439.

42. Zhao Y, Lai W, Xu Y, Li L, Chen Z, Wu W. Exogenous and endogenous therapeutic effects of combination sodium ferulate and bone marrow stromal cells (BMSCs) treatment enhance neurogenesis after rat focal cerebral ischemia. Metab Brain Dis. 2013;28:655-66.

43. Xing Y, Chen X, Cao Y, Huang J, Xie X, Wei Y. Expression of Wnt and notch signaling pathways in inflammatory bowel disease treated with mesenchymal stem cell transplantation: evaluation in a rat model. Stem Cell Res Ther. 2015;6:101.

44. Liu S, Liu D, Chen C, Hamamura K, Moshaverinia A, Yang R, Liu Y, Jin Y, Shi S. MSC transplantation improves osteopenia via epigenetic regulation of notch signaling in lupus. Cell Metab. 2015;22:606-18.

45. Dai C, Liang D, Li H, Sasaki M, Dawson TM, Dawson VL. Functional identification of neuroprotective molecules. PLoS One. 2010:5:e15008.

46. Chi Z, Byrne ST, Dolinko A, Harraz MM, Kim MS, Umanah G, Zhong J, Chen $\mathrm{R}$, Zhang J, Xu J, et al. Botch is a gamma-glutamyl cyclotransferase that deglycinates and antagonizes notch. Cell Rep. 2014;7:681-8. 
47. Chi Z, Zhang J, Tokunaga A, Harraz MM, Byrne ST, Dolinko A, XU J, Blackshaw S, Gaiano N, Dawson TM, Dawson VL. Botch promotes neurogenesis by antagonizing notch. Dev Cell. 2012;22:707-20.

48. Mei B, Li H, Zhu J, Yang J, Yang Z, Wen Z, Li X, Shen H, Shen M, Chen G. Neuroprotection of botch in experimental intracerebral hemorrhage in rats. Oncotarget. 2017:8:95346-60.

49. Bederson JB, Germano IM, Guarino L. Cortical blood flow and cerebral perfusion pressure in a new noncraniotomy model of subarachnoid hemorrhage in the rat. Stroke. 1995;26:1086-91. 1091-1092

50. Alhadlaq A, Mao JJ. Mesenchymal stem cells: isolation and therapeutics. Stem Cells Dev. 2004;13:436-48.

51. Liu N, Zhang Y, Fan L, Yuan M, Du H, Cheng R, Liu D, Lin F. Effects of transplantation with bone marrow-derived mesenchymal stem cells modified by Survivin on experimental stroke in rats. J Transl Med. 2011; 9:105.

52. Xie Z, Huang L, Enkhjargal B, Reis C, Wan W, Tang J, Cheng Y, Zhang JH. Recombinant Netrin-1 binding UNC5B receptor attenuates neuroinflammation and brain injury via PPARgamma/NFkappaB signaling pathway after subarachnoid hemorrhage in rats. Brain Behav Immun. 2018 69:190-202.

53. Wang Z, Huang W, Zuo Z. Perioperative aspirin improves neurological outcome after focal brain ischemia possibly via inhibition of notch 1 in rat. J Neuroinflammation. 2014;11:56.

54. Garcia JH, Wagner S, Liu KF, Hu XJ. Neurological deficit and extent of neuronal necrosis attributable to middle cerebral artery occlusion in rats. Statistical validation. Stroke. 1995;26:627-34. 635

55. Sugawara T, Ayer $\mathrm{R}$, Jadhav $\mathrm{V}$, Zhang JH. A new grading system evaluating bleeding scale in filament perforation subarachnoid hemorrhage rat model. J Neurosci Methods. 2008;167:327-34.

56. Guo D, Wilkinson DA, Thompson BG, Pandey AS, Keep RF, Xi G, Hua Y. MRI characterization in the acute phase of experimental subarachnoid hemorrhage. Transl Stroke Res. 2017:8:234-43.

57. Muroi C, Kashiwagi Y, Rokugawa T, Tonomura M, Obata A, Nevzati E, Tsuboi A, Okuchi K, Mishima K, Abe K, Fujioka M. Evaluation of a filament perforation model for mouse subarachnoid hemorrhage using 7.0 Tesla MRI. J Clin Neurosci. 2016;28:141-7.

58. Chen Y, Zhang Y, Tang J, Liu F, Hu Q, Luo C, Tang J, Feng H, Zhang JH. Norrin protected blood-brain barrier via frizzled-4/beta-catenin pathway after subarachnoid hemorrhage in rats. Stroke. 2015;46:529-36.

59. Xie $Y$, Liu W, Zhang $X$, Wang $L$, Xu L, Xiong $Y$, Yang L, Sang H, Ye R, Liu X. Human albumin improves long-term behavioral sequelae after subarachnoid hemorrhage through neurovascular remodeling. Crit Care Med. 2015;43:e440-9.

60. Xie Y, Guo H, Wang L, Xu L, Zhang X, Yu L, Liu Q, Li Y, Zhao N, Zhao N, et al. Human albumin attenuates excessive innate immunity via inhibition of microglial Mincle/Syk signaling in subarachnoid hemorrhage. Brain Behav Immun. 2017;60:346-60.

61. Chamorro A, Meisel A, Planas AM, Urra X, van de Beek D, Veltkamp R. The immunology of acute stroke. Nat Rev Neurol. 2012;8:401-10.

62. Lucke-Wold BP, Logsdon AF, Manoranjan B, Turner RC, McConnell E, Vates $\mathrm{GE}$, Huber JD, Rosen CL, Simard JM. Aneurysmal subarachnoid hemorrhage and neuroinflammation: a comprehensive review. Int J Mol Sci. 2016;17:497.

63. Frontera JA, Aledort L, Gordon E, Egorova N, Moyle H, Patel A, Bederson JB, Sehba F. Early platelet activation, inflammation and acute brain injury after a subarachnoid hemorrhage: a pilot study. J Thromb Haemost. 2012;10:711-3.

64. Torrente Y, Polli E. Mesenchymal stem cell transplantation for neurodegenerative diseases. Cell Transplant. 2008;17:1103-13.

65. Tang XD, Shi L, Monsel A, Li XY, Zhu HL, Zhu YG, Qu JM. Mesenchymal stem cell microvesicles attenuate acute lung injury in mice partly mediated by Ang-1 mRNA. Stem Cells. 2017;35:1849-59.

66. Ding J, Chen B, Lv T, Liu X, Fu X, Wang Q, Yan L, Kang N, Cao Y, Xiao R. Bone marrow mesenchymal stem cell-based engineered cartilage ameliorates polyglycolic acid/polylactic acid scaffold-induced inflammation through M2 polarization of macrophages in a pig model. Stem Cells Transl Med. 2016;5:1079-89.

67. Acosta SA, Tajiri N, Hoover J, Kaneko Y, Borlongan CV. Intravenous bone marrow stem cell grafts preferentially migrate to spleen and abrogate chronic inflammation in stroke. Stroke. 2015;46:2616-27.

68. Marfia G, Navone SE, Hadi LA, Paroni M, Berno V, Beretta M, Gualtierotti R, Ingegnoli $F$, Levi $V$, Miozzo $M$, et al. The adipose mesenchymal stem cell secretome inhibits inflammatory responses of microglia: evidence for an involvement of Sphingosine-1-phosphate Signalling. Stem Cells Dev. 2016; 25:1095-107.

69. Kim Y, Jo SH, Kim WH, Kweon OK. Antioxidant and anti-inflammatory effects of intravenously injected adipose derived mesenchymal stem cells in dogs with acute spinal cord injury. Stem Cell Res Ther. 2015;6:229.

70. Ilagan MX, Kopan R. SnapShot: notch signaling pathway. Cell. 2007;128:1246

71. Xu H, Zhu J, Smith S, Foldi J, Zhao B, Chung AY, Outtz H, Kitajewski J, Shi C, Weber $\mathrm{S}$, et al. Notch-RBP-J signaling regulates the transcription factor IRF8 to promote inflammatory macrophage polarization. Nat Immunol. 2012;13: 642-50.

72. Nam HS, Kwon I, Lee BH, Kim H, Kim J, An S, Lee OH, Lee PH, Kim HO,

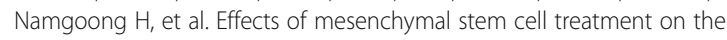
expression of matrix metalloproteinases and angiogenesis during ischemic stroke recovery. PLoS One. 2015;10:e144218.

73. Chung TN, Kim JH, Choi BY, Chung SP, Kwon SW, Suh SW. Adipose-derived mesenchymal stem cells reduce neuronal death after transient global cerebral ischemia through prevention of blood-brain barrier disruption and endothelial damage. Stem Cells Transl Med. 2015;4:178-85.

74. He B, Yao Q, Liang Z, Lin J, Xie Y, Li S, Wu G, Yang Z, Xu P. The dose of intravenously transplanted bone marrow stromal cells determines the therapeutic effect on vascular remodeling in a rat model of ischemic stroke. Cell Transplant. 2016;25:2173-85.

\section{Ready to submit your research? Choose BMC and benefit from:}

- fast, convenient online submission

- thorough peer review by experienced researchers in your field

- rapid publication on acceptance

- support for research data, including large and complex data types

- gold Open Access which fosters wider collaboration and increased citations

- maximum visibility for your research: over $100 \mathrm{M}$ website views per year

At BMC, research is always in progress.

Learn more biomedcentral.com/submissions 